\title{
High Temperature Ultralow Water Content Carbon Dioxide-in-Water \\ Foam Stabilized with Viscoelastic Zwitterionic Surfactants
}

\author{
Shehab Alzobaidii ${ }^{1}$, Chang $\mathrm{Da}^{1}, \mathrm{Vu} \operatorname{Tran}^{1}$, Maša Prodanović ${ }^{2}$, and Keith P. \\ Johnston $^{1, *}$
}

\section{Keywords:}

CO2-in-water foam, High internal phase foam, Surfactant-stabilized foam, Foam stability, Viscosity, Wormlike micelles, Viscoelastic.

\section{Abstract}

Ultralow water content carbon dioxide- in-water (C/W) foams with gas phase volume fractions $(\phi)$ above 0.95 (that is $<0.05$ water) tend to be inherently unstable given that the large capillary pressures that cause the lamellar films to thin. Herein, we demonstrate that these C/W foams may be stabilized with viscoelastic aqueous phases formed with a single zwitterionic surfactant at a concentration of only $1 \%(\mathrm{w} / \mathrm{v})$ in DI water and over a wide range of salinity. Moreover, they are stable with a foam quality $\phi$ up to 0.98 even for temperatures up to $120^{\circ} \mathrm{C}$. The properties of aqueous viscoelastic solutions and foams containing these solutions are examined for a series of zwitterionic amidopropylcarbobetaines, $\mathrm{R}-\mathrm{ONHC}_{3} \mathrm{H}{ }_{6} \mathrm{~N}\left(\mathrm{CH}_{3}\right)_{2} \mathrm{CH}_{2} \mathrm{CO}_{2}$, where $\mathrm{R}$ is varied from $\mathrm{C}_{12-14}$ (coco) to $\mathrm{C}_{18}$ (oleyl) to $\mathrm{C}_{22}$ (erucyl). For the surfactants with long $\mathrm{C}_{18}$ and $\mathrm{C}_{22}$ tails, the relaxation times from complex rheology indicate the presence of viscoelastic wormlike micelles over a wide range in salinity and $\mathrm{pH}$, given the high surfactant packing fraction. The apparent viscosities of these ultralow water content foams reached more than 
$\mathrm{C}_{12-14}$ surfactant. At $90^{\circ} \mathrm{C}$, the foam morphology was composed of $\sim 35 \mu \mathrm{m}$ diameter bubbles with a polyhedral texture. The apparent foam viscosity typically increased with $\phi$ and then dropped at $\phi$ values higher than 0.95 to 0.98 . The Ostwald ripening rate was slower for foams with viscoelastic versus non-viscoelastic lamellae as shown by optical microscopy, as a consequence of slower lamellar drainage rates. The ability to achieve high stabilities for ultralow water content C/W foams over a wide temperature range is of interest in various technologies including polymer and materials science, $\mathrm{CO}_{2}$ enhanced oil recovery, $\mathrm{CO}_{2}$ sequestration (by greater control of the $\mathrm{CO}_{2}$ flow patterns), and possibly even hydraulic fracturing with minimal use of water to reduce the requirements for wastewater disposal.

\section{Introduction}

Supercritical carbon dioxide $\left(\mathrm{CO}_{2}\right)$ in water $(\mathrm{C} / \mathrm{W})$ foams (also referred to as emulsions) are of interest in many applications including materials synthesis ${ }^{1}$, pharmaceutical and medical applications $^{2}$, carbon dioxide sequestration ${ }^{3,4}$, enhanced oil recovery ${ }^{5,6}$, and as energized fluids for hydraulic fracturing in reservoirs ${ }^{7}$. A variety of surface active materials including surfactants $^{8}$, nanoparticles ${ }^{9,10}$, and proteins ${ }^{11}$ have been used to stabilize $\mathrm{C} / \mathrm{W}$ foams by slowing lamellar drainage and thinning that accelerate Oswald ripening and coalescence. At low water volume fractions (high gas fractions $\phi$ often referred to as foam qualities) foams become less stable as the liquid lamellae between polyhedral shaped gas cells become very thin. ${ }^{12}$ For $\phi$ approaching unity, the capillary pressure $P_{c}=\gamma / R_{f}(1-\phi)^{0.5}$, where $\gamma$ is interfacial tension, and $R_{f}$ is the lamella radius, becomes very large. ${ }^{13}$ This large $P_{c}$ is the driving force for drainage of the lamellae films to the plateau borders. Thus it may cause rapid thinning of the lamellae, leading to coalescence and/or Ostwald ripening. ${ }^{13}$ This film drainage is even more rapid at high temperatures given the decrease in the viscosity of the aqueous phase. ${ }^{14}$

The viscosity and stability of foams may be enhanced with viscoelastic aqueous phases comprised of entangled wormlike micelles. ${ }^{15,16}$ For an aqueous surfactant solution, an increase in the packing parameter $p=v / a_{0} l_{c}$, of the surfactant to $1 / 3<p<1 / 2$ can induce a transition from spherical to long cylindrical (wormlike) micelles, where $v$ is the volume of monomer tail, $l_{c}$ 
is the tail length and $a_{0}$ is the head group area. ${ }^{17}$ For ionic surfactants this transition can be triggered by reducing $a_{0}$ upon adding electrolytes ${ }^{18}$ or by combining an anionic and cationic surfactant to reduce head group electrostatic repulsion. ${ }^{15,16,19,20}$ For switchable amine surfactants, smart wormlike micelles can also be formed by lowering the $\mathrm{pH}$ to protonate the head group with $\mathrm{CO}_{2}$ at low pressure ${ }^{19,21}$, or by adding $\mathrm{HCl}^{22,23}$. Wormlike micelles can also be formed with a single surfactant in the case of zwitterionic surfactants given the lower values of $a_{0}$ (lack of electrostatic repulsion) than for ionic surfactants, although they have received little attention. $^{24}$

To prevent destabilization of foams at atmospheric pressure, high concentrations of viscoelastic surfactants or polymer solutions have been used to maintain thicker lamellae by retarding drainage and raising the disjoining pressure. ${ }^{25,26,27,28}$ Highly stable air/water foams at atmospheric pressure have been formed with viscoelastic wormlike micelles utilizing high concentrations of mixtures of cationic and anionic surfactants or single ionic surfactants with added salts. $^{29,30,31}$ Only very recently, high pressure C/W foams with viscoelastic aqueous phases composed of wormlike micelles have been reported with apparent viscosities > $100 \mathrm{cP}$ at $25^{\circ} \mathrm{C}^{28}$ and temperatures up to $50^{\circ} \mathrm{C}^{27}$. The apparent viscosities were much larger than those of $\mathrm{C} / \mathrm{W}$ foam with non-viscoelastic nonionic surfactants with ethylene oxide head groups ${ }^{8}$ or with protonated amines. ${ }^{32}$

It was found recently that ultralow water content foams with foam qualities up to 0.98 may be stabilized with viscoelastic aqueous phases, despite the high $P_{c}{ }^{28}$ It appeared that the maintenance of thicker lamellae films, as a consequence of slower drainage, decreased the Ostwald ripening rate. ${ }^{28}$ However, it was necessary to use a mixture of cationic and anionic surfactant with a high total concentration of $4 \mathrm{wt} \%$ and relatively high salinities. In another approach, ultralow water content foam foams were stabilized with a mixture of partially hydrolyzed polyacrylamide (HPAM), surfactants, and silica nanoparticles to form a viscoelastic aqueous phase. ${ }^{27}$ To build upon these advances, novel concepts are needed to design surfactants to increase foam stabilities at more challenging conditions including high foam qualities, a wide range in salinity, low surfactant concentrations, and high temperatures. 
Relative to ionic and nonionic surfactants ${ }^{33}$, extremely few studies of $\mathrm{C} / \mathrm{W}$ foams have examine zwitterionic surfactants, even though they are known to be very effective for low pressure gas foams. ${ }^{34}$ For example, non-viscoelastic zwitterionic surfactants solutions have been previously used for $\mathrm{C} / \mathrm{W}$ foam at ambient temperature with high viscosities at qualities less than 0.9. ${ }^{35}$ A potential advantage of zwitterionic versus ionic surfactants, in addition to lower surfactant packing fractions, is that they can be less prone to precipitation at high temperature and salinity. ${ }^{36}$ This type of phase behavior has been investigatged for analogous ionic and zwitterionic polymers. Whereas ionic polyelectrolytes contract and precipitate with added salt, as ions screen electrostatic repulsion, zwitterionic polymers expand with added salt, the "antipolyelectrolyte effect". Here the added electrolyte screens dipolar attraction between the zwitterions resulting in increased hydration. As temperature increases the gain in entropy upon breaking these dipoles becomes more prevalent again favoring solvation. ${ }^{37,}{ }^{38}$ Finally, zwitterionic surfactants can be environmental benign and biodegradable. ${ }^{17,39}$

The objective of this study is to examine the influence of tail length on the viscoelastic properties, via wormlike micelle formation, of an aqueous phase for a series of amidopropyl betaine zwitterionic surfactants and to determine their effect on the stability of ultralow water content C/W foams. The capillary pressure effect on apparent foam viscosity and stability of the foams is studied by varying the foam quality from 0.7 to 0.98 for temperatures up to $120^{\circ} \mathrm{C}$. Herein we demonstrate that a single dilute ( $1 \mathrm{wt} . \% \mathrm{w} / \mathrm{v})$ zwitterionic surfactant with a carboxybetaine head group and a long tail, either oleylamidopropyldimethyl betaine (OAPB, $\mathrm{C}_{18}$ tail) or erucylamidopropyldimethyl betaine (EAPB, $\mathrm{C}_{22}$ tail) may be used to form viscoelastic aqueous solutions that enable stabilization of highly viscous $\mathrm{C} / \mathrm{W}$ foams even for qualities up to 0.98 and over a wide range of salinity. The viscoelastic aqueous phases, composed of wormlike micelles, are characterized by steady state and complex rheology with a cone-and-plate rheometer, can be formed at unusually low surfactant concentrations of only $1 \%(w / v)$, given the low $a_{0}$ for EAPB and OAPB. In contrast, wormlike micelles are not formed with the same surfactant head group but with a shorter tail $\left(\mathrm{C}_{12-14}\right)$ (cocoamidopropyldimethyl betaine, (CAPB). The aqueous phase behavior for the surfactants is tested up to $120^{\circ} \mathrm{C}$ and $22 \%$ total dissolved solids (TDS) including divalent ions. Optical microscopy at high pressure is used to 
determine the foam texture and to quantify the rate of Ostwald ripening over a range of several hours. Even at high qualities up to 0.95 , the rate of Ostwald ripening is shown to be lowered by the viscoelastic lamellae.

\section{Experimental Methods}

Materials. OAPB, Lot \# WI4D13X06, was received from Solvay as $28.5-32 \% \mathrm{w} / \mathrm{v}$ OAPB concentration, $16-18 \%$ w/v propylene glycol, 1.5-2.5\% w/v Glycerin, and the remainder water. All the concentrations (\%) used in this study are in terms of weight by volume $(\% \mathrm{w} / \mathrm{v})$. A concentration of $31 \%$ OAPB was assumed in this study. CAPB and EAPB were also gifts from Solvay. CAPB solution was received as $39.4 \%$ and EAPB was received as $100 \%$ concentration. The chemical structures of CAPB, OAPB, and EAPB are given in Table 1. The chemical structures were drawn using ChemBioDraw Ultra software package version 14.0. Synthetic seawater (SSW, Cat. No.8363-5, Lot 1306873, ASTM D1141, pH 8.2, Ricca Chemical Co.) was used as received. Deionized (DI) water (Nanopure II, Barnstead, Dubuque, IA) was used for all experiments. Potassium chloride $(\mathrm{KCl})$, sodium chloride $(\mathrm{NaCl})$, calcium chloride dehydrate $\left(\mathrm{CaCl}_{2} \cdot 2 \mathrm{H}_{2} \mathrm{O}\right), 1 \mathrm{~N}$ solution hydrochloric acid $(\mathrm{HCl})$, and $1 \mathrm{~N}$ solution sodium hydroxide $(\mathrm{NaOH})$ were obtained from Fisher scientific. $\mathrm{CO}_{2}$ was purchased from Matheson with $99.99 \%$ purity. The pKa of the carboxylic acid group in all the surfactants used in this study is about $\mathrm{pH} 1.8$, thus the surfactants were in the zwitterionic state in the $\mathrm{pH}$ ranges in this study, with some cationic surfactant at $\mathrm{pH} 2 .^{40}$

Cloud Point Determination. Cloud point tests for $1 \% \mathrm{w} / \mathrm{v}$ surfactant at $120^{\circ} \mathrm{C}$ in different salinities were done using \#7 Ace-Thread thick walled high pressure glass tubes and PTFE Plug with FETFE O-Ring rated for $120^{\circ} \mathrm{C}$ and 150 psig, purchased from Ace Glass Inc., over a period of two days. Each tube was observed visually to determine if the solution was turbid or clear. If the tube was clear, then the cloud point was above $120^{\circ} \mathrm{C}$.

High pressure Interfacial Tension Measurements. For the surfactants used in this study, the $\mathrm{CO}_{2}$ and the surfactant solutions in $2 \% \mathrm{KCl}$ interfacial tension measurements were done at 3000 psig and $24^{\circ} \mathrm{C}$. Theta Optical Tensiometer apparatus from Biolin Scientific was utilized for these measurements. The interfacial tension (IFT) measurements were obtained using 
axisymmetric drop shape analysis of a reverse pendant $\mathrm{CO}_{2}$ drop as show in Figure $\mathrm{S} 1$ in supplemental material. The aqueous solution was initially saturated with $\mathrm{CO}_{2}$, and each $\mathrm{CO}_{2}$ drop was let to equilibrate with the aqueous solution for about 30 minutes until a steady state measurement is obtained. The drop shape was analyzed with the young/Laplace equation equipped with the OneAttension software package (Biolin Scientific). Minimum of three measurements for each condition were recorded and the average value is reported.

Aqueous Phase Rheology Measurement. Steady state shear viscosity and oscillatory measurements for the viscoelastic systems were determined using AR G2 rheometer (TA Instruments) with cone-and-plate geometry $\left(44 \mathrm{~mm}, 2^{\circ}\right)$. All the measurements were obtained at $25 \mathrm{C}$ and ambient pressure. $1 \mathrm{~N} \mathrm{HCl}$ solution was used to lower the $\mathrm{pH}$ of the aqueous phase solutions. Each steady state point was equilibrated for a maximum of 60 seconds. For steady state shear viscosity measurements, the shear rate was increased from 0.1 to about $200 \mathrm{~s}^{-1}$. Each frequency sweep was from $0.1 \mathrm{rad} / \mathrm{s}$ to $600 \mathrm{rad} / \mathrm{s}$ for oscillatory measurements, and the reported data emphasized the crossover point.

\section{C/W Foam Formation and Apparent Viscosity Measurements. C/W foam was} generated and characterized using the flow system in previous studies Figure $1 .{ }^{28}$ Isco syringe pumps (Model 100DX, Model 260D) were used to pump the liquid and gas phases to the foam generator. A beadpack, with 22 Darcy (D) permeability, composed of 180- $\mu$ m-diameter spherical glass beads (70-100 mesh soda-lime silica glass and stock \# P-0080 from Potters Industries Inc.), was used to generate the $\mathrm{C} / \mathrm{W}$ foams for all the experiments. The glass beadpack was $0.38 \mathrm{~cm}$ in diameter and $11.3 \mathrm{~cm}$ in length. The porosity of the beadpack was 0.34 , and the pore volume was $0.45 \mathrm{~mL}$. At a flow rate of $0.5 \mathrm{~mL} / \mathrm{min}$ (corresponding to a residence time of $54 \mathrm{~s}$ ) the superficial velocity was $200 \mathrm{ft} / \mathrm{day}$, and the beadpack shear rate was about $400 \mathrm{~s}^{-1}$. The beadpack was connected to a $195 \mathrm{~cm}$ long by $762 \mu \mathrm{m}$ inside diameter capillary tube with a volume of $0.89 \mathrm{ml}$. For the flow rate of $0.5 \mathrm{~mL} / \mathrm{min}$, the resident time was 107 seconds. At this flow rate the capillary tubes' shear rate was $200 \mathrm{~s}^{-1}$. For accuracy, two differential pressure transducers were used to measure the pressure drop across the capillary tubes. The apparent foam viscosity in the capillary tubes was calculated from the pressure drop 
across the capillary tubes using the Hagen-Poiseuille equation. All experiments were measured at a pressure of 3000 psig \pm 50 and a temperature of $50^{\circ} \mathrm{C}$ or $90^{\circ} \mathrm{C}$.

Determination of C/W Foam Morphology and Stability. The foam generated in the glass beadpack was directed and captured at room temperature, or high temperature using a holder, with high pressure microscopy sapphire cell described previously. ${ }^{28}$ For the viscoelastic systems used in this study, the foam stability was tested over a longer period of time until noticeable foam destabilization was observed. ImageJ software was used to determine the size of each bubble. The Sauter mean diameter $\left(D_{s m}\right)$ of foam bubbles was calculated as follows:

$$
D_{s m}=\frac{\sum_{i} D_{i}{ }^{3}}{\sum_{i} D_{i}{ }^{2}}
$$

where $D_{i}$ is the diameter of a given foam bubble.

\section{Results and Discussion}

Shear Moduli and Zero Shear Viscosity of Surfactant Solutions. In order to identify the presence and degree of entanglement of wormlike micelles, the elastic storage $G^{\prime}$ and loss G" shear moduli were studied. For a Maxwell fluid

$$
\begin{aligned}
& G^{\prime}(\omega)=\frac{\omega^{2} \tau_{R}^{2}}{1+\omega^{2} \tau_{R}^{2}} G_{0} \\
& G^{\prime \prime}(\omega)=\frac{\omega \tau_{R}}{1+\omega^{2} \tau_{R}^{2}} G_{0} \\
& G^{\prime \prime}(\omega) / G^{\prime}(\omega)=1 / \omega \tau_{R}
\end{aligned}
$$

where $\mathrm{G}_{0}$ is the plateau of the storage modulus in the high frequency limit and $\tau_{R}$ is the relaxation time. The storage modulus plateau is related to the number density of the entanglement points $(v)$ by $\mathrm{G}_{0}=v k T$. A single $\tau_{R}$ is used to describe both reputation and micelle scission/recombination. ${ }^{28}$ As the micelles become more entangled, the crossing of the storage and loss moduli shifts to lower frequencies given the larger increase in $G^{\prime}(\omega)$. The storage modulus did not reach plateau in all our surfactants systems over the range of $\omega$ studied, so the relaxation times were calculated based on Equation $4 .{ }^{41}$ 
Salt Effect. Although the effect of salt on viscoelasticity is well known for ionic surfactants such as $\mathrm{SLES}^{28}$, it has received little attention for carboxybetaine surfactants. ${ }^{24}$ For EAPB, viscoelastic wormlike micelles have been observed by cryo-TEM even at concentrations as low as $50 \mathrm{mM}$ in deionized water. ${ }^{24} \mathrm{~A}$ crossover frequency for EAPB was not present within the frequency range shown in Figure S4 as it is known to occur at very low frequencies on the order of $10^{-2} \mathrm{rad} / \mathrm{s}^{42,43}$ With the very long $\mathrm{C}_{22}$ tail, the packing parameter is sufficiently large in DI water for the formation of cylindrical or wormlike micelles. Furthermore, it was found that the frequency spectra in the dynamic rheology did not change with $\mathrm{NaCl}$ up to $0.3 \%$ concentration of salt in the surfactant solution. ${ }^{24}$ Similarly in Figure S3(A), the change in viscosity was negligible upon increasing the $\mathrm{KCl}$ concentration from $2 \%$ to $10 \%$. However, when divalent ions, $\mathrm{Ca}^{+2}$, were added to the solution in API brine, a small twofold increase of viscosity was noted at the lowest shear rate.

For $1 \%$ OAPB in DI water, the crossover frequency was $19 \mathrm{rad} / \mathrm{s}$. For $2 \% \mathrm{KCl}$ it decreased slightly to $16 \mathrm{rad} / \mathrm{s}$, and with high salinity (API brine) it decreased markedly to $1.2 \mathrm{rad} / \mathrm{s}$, shown in Figure 3, with corresponding relaxation times estimated by the Maxwell model of $52 \mathrm{~ms}$, $63 \mathrm{~ms}$, and $840 \mathrm{~ms}$ respectively. The Cole-Cole plot is shown in Figure S5. Steady state viscosity values versus shear rate measurements were investigated over a range of $\mathrm{pH}$ in DI water or with added electrolytes. In DI water shown in Figure 2(A) and Table 2, the zero shear viscosity was $70 \mathrm{cP}$ at a low shear rate and it decreased with shear rate indicating shear thinning, as the entanglement of the micelles is weakened. As inorganic salts are added, the zero shear viscosity increased from $70 \mathrm{cP}$ in DI water to $90 \mathrm{cP}$ in $2 \% \mathrm{KCl}, 140 \mathrm{cP}$ in SSW, and then increased markedly to $2300 \mathrm{cP}$ in $2 \% \mathrm{CaCl}_{2}$ and $8 \% \mathrm{NaCl}(\mathrm{API})$ brine shown in Figure 2(A).

For both surfactants, the high viscosities, low crossover frequencies and high $\tau_{R} s$ indicate the presence of wormlike micelles at all salinities, based on previous studies of these properties for a wide range of surfactants. ${ }^{28}$ At low shear rates the viscosities were over an order of magnitude higher than would be observed with spherical micelles. The alignment of the zwitterionic head groups on the surface of the wormlike micelles will cause the cations to be somewhat closer to each other and the same for the anions in the zwitterionic tips, as shown in Figure 4. However, the electrostatic repulsion from these dipole-dipole interactions for these 
head groups will be lower than in the case of ionic surfactants, resulting in smaller $a_{0}$ values and larger packing parameters. Thus, these zwitterionic surfactants form wormlike micelles at lower salinities and in DI water, whereas they only form at high salinities for ionic surfactants, or with mixtures of cationic and anionic headgroups.

The relatively modest salt effect on the rheological properties for OAPB and very slight effect for EAPB may be attributed to screening of the two charges on each head group which would weaken the dipole-dipole repulsion illustrated in Figure 4. The aqueous phase viscosity has been increased by adding high concentrations of inorganic salts for amine oxide zwitterionic surfacants and for polymers with carboxybetaines monomers. ${ }^{44,45,46,47}$ The decrease in $a_{o}$ with salinity may be expected to produce longer and more entangled wormlike micelles, ${ }^{16,22,48,49}$ as was also evident in the decrease in the crossover frequency in Figure 3. This change in packing parameter plays a larger role for OAPB with smaller packing parameters as a consequence of the shorter tail. The effect of salt on the dipole-dipole interactions is accentuated for divalent ions given greater charge screening. In DI water, as the tail length was increased up to $\mathrm{C}_{18}$ for the carboxybetaines, the length of wormlike micelles and degree of entanglement increased. ${ }^{41}$ Based on these results, a salt concentration of $2 \% \mathrm{KCl}$ was chosen for most of the remaining experiments in this study, and it was not varied given the weak effect of salt, especially at higher shear rates. In the case of polycarbobetaine polymers, the addition of monovalent salt screens attractive interactions between zwitterion dipoles leading to chain expansion, the anti-polyelectrolyte effect. ${ }^{4}$ However, the dipole-dipole interactions are attractive given that the cations are attracted preferentially to the anionics, given the flexibility of the polymer.

Concentration Effect. As the concentration of OAPB in $2 \% \mathrm{KCl}$ was increased from $1 \%$ to $3 \%$, the crossing of $\mathrm{G}^{\prime}$ and $\mathrm{G}^{\prime \prime}$ shifted to lower frequency, from $15.85 \mathrm{rad} / \mathrm{s}$ down to $1.59 \mathrm{rad} / \mathrm{s}$ at 3\% Figure 5(A). The Cole-Cole plot in Figure 5(C) illustrates Maxwell behavior. Each of these frequencies is low indicating the formation of wormlike micelles. Adding more surfactant monomers to the solution raises the number and entanglement of the wormlike micelles producing the lower crossover frequency. Eventually at only 0.1\% OAPB, as shown in Figure S2, the zero shear viscosity of $\mathrm{OAPB}$ in $2 \% \mathrm{KCl}$ is only $2 \mathrm{cP}$ at indicating spherical micelles or short 
non-entangled rodlike micelles. For $3 \%$ OAPB where $\tau_{R}$ is the largest, the viscosity is $>1000 \mathrm{cP}$ indicating highly entangled wormlike micelles (Figure S2). The increase in the number of wormlike micelles and the entanglements results in increasing viscosity of the solution. ${ }^{45}$ Given these results, a concentration of $1 \%$ surfactant was chosen as the standard surfactant concentration throughout this study.

PH Effect. When the $\mathrm{pH}$ of the OAPB solution is reduced from $\mathrm{pH} 7.25$ to $\mathrm{pH} 4$, the crossover frequency decreased only slightly from $15.8 \mathrm{rad} / \mathrm{s}$ to $11.6 \mathrm{rad} / \mathrm{s}$ Figure 5(B) with the Cole-Cole plot in figure 5 (D). The corresponding relaxation time increased from $63 \mathrm{~ms}$ to $86 \mathrm{~ms}$. Over this range, the carboxylate group is not protonated and thus $\mathrm{pH}$ has little influence on the head group interactions. $^{40}$

The $\mathrm{pH}$ of $1 \%$ OAPB in $2 \% \mathrm{KCl}$ without adjustment was 7.25 , and that for $1 \% \mathrm{EAPB}$ in $2 \% \mathrm{KCl}$ was 9.8 Figure S3. The viscosity of OAPB in $2 \% \mathrm{KCl}$ at pH 7.25 was $90 \mathrm{cP}$ and at $\mathrm{pH} 4$ was $200 \mathrm{cP}$ as shown in Figure 2(B). A further decrease in $\mathrm{pH}$ to 2 increased the viscosity to $5200 \mathrm{cP}$. An example of the difference for a viscous and a non-viscous surfactant solution is shown with photographs of flow in Figure S7. For $1 \%$ EAPB in $2 \% \mathrm{KCl}$ the viscosity increased by a much smaller percentage, from $2250 \mathrm{cP}$ at $\mathrm{pH}$ of 9.8 , to $4400 \mathrm{cP}$ at $\mathrm{pH} 4$. As the $\mathrm{pH}$ decreases close to the $\mathrm{pKa}^{40}$ value, the cationic protonated head groups form attractive interactions with the zwitterionic dipoles of the unprotonated fraction. This interaction decreases $a_{o}$ and increases the packing parameter and formation and growth of wormlike micelles ${ }^{22,44}$ Furthermore, the protonated carboxylic acid groups may form hydrogen bonds with the non-protonated carboxylic acid groups in unprotonated surfactant. ${ }^{50,51}$ Similar $\mathrm{pH}$ behavior on viscosity has been observed previously for surfactants containing carboxybetaine heads and for carbobetaine polymers. $^{46,52}$

The viscosities of the surfactant solutions at a shear rate $200 \mathrm{~s}^{-1}$ (Table 2) are of particular relevance in this study, as this is a common shear rate for fluids in hydraulic fracturing. At this shear rate, the aqueous phase viscosity ranged from $8 \mathrm{cP}$ to $32.5 \mathrm{cP}$ for EAPB and OAPB indicating that entanglement of the wormlike micelles was still present. However, for 
CAPB with a short tail and lower packing fraction, the viscosity was only about $1 \mathrm{cP}$ indicating wormlike micelles were not formed Table 5.

Influence of Dissolved Carbon Dioxide on Aqueous Phase Rheology. The effect of dissolved carbon dioxide on the viscoelastic properties of the aqueous surfactant solutions was studied with flowing surfactant solution in the apparatus described in Figure S6, following our earlier procedure. ${ }^{28}$ The 22D beadpack was bypassed to flow the solution directly to the capillary tube and the viscosity was measured at $200 \mathrm{~s}^{-1}$. To mimic conditions in the foam generation experiments, $1 \%$ OAPB in $2 \% \mathrm{KCl}$ solution was equilibrated with $\mathrm{CO}_{2}$ at room temperature and 3000 psig overnight. The measured viscosity was $12 \mathrm{cP}$, which is very similar to the value of 11.6 $\mathrm{cP}$ from the cone and plate rheometer at $\mathrm{pH} 4$ and $200 \mathrm{~s}^{-1}$ without the presence of $\mathrm{CO}_{2}$. The same behavior was observed at $50^{\circ} \mathrm{C}$ indicating wormlike micelles were present, but at $90^{\circ} \mathrm{C}$ it was not possible to regulate the pressure. Thus, $\mathrm{CO}_{2}$ did not have a significant influence on the rheological properties of the wormlike micelles. Although a previous study showed that $\mathrm{CO}_{2}$ swells wormlike micelles of surfactants formed with potassium carboxylate perfluoropolyether, the weaker interactions of $\mathrm{CO}_{2}$ with hydrocarbon surfactants did not perturb the viscosity of the micelles in our study. ${ }^{53} \mathrm{~A}$ smaller degree of swelling for hydrocarbon versus fluorocarbon tails may be expected given the greater solvation of the latter.

C/W Interfacial Tension Measurements. For a solution of $1 \%$ OAPB in $2 \% \mathrm{KCl}$, the interfacial tension $\gamma$ at the $\mathrm{C} / \mathrm{W}$ interface is lowered from $20 \mathrm{mN} / \mathrm{m}$ without surfactant to $3.9 \mathrm{mN} / \mathrm{m}$ (Figure 6). A minimum of three IFT measurement trails for each surfactant solution was recorded, and the average value is reported. For $1 \%$ CAPB in $2 \% \mathrm{KCl}, \gamma$ was lowered to 5.8 $\mathrm{mN} / \mathrm{m}$, and for $1 \%$ EAPB in $2 \% \mathrm{KCl}$, to only $6.8 \mathrm{mN} / \mathrm{m}$ Figure 6 . Furthermore, the area/surfactant from the Gibbs adsorption equation is smaller for CAPB than the other two, given the smaller area of the shorter tails. The larger $\gamma$ for EAPB may be due to the lower packing and to weaker solvation of the longer $\mathrm{C}_{22}$ tail of EAPB. Another reason might be due to the impurities that were present in the OAPB solution, which might reduce $\gamma$. The much higher critical micelle concentration of $0.2 \mathrm{mM}$ for EAPB may be expected given the greater penalty for bending the micelle interface about longer tails. In a previous study, the surface tensions for OAPB and EAPB were found to be similar; ${ }^{54}$ however the average area at the air/ $\mathrm{W}$ interface 
decreased from 0.46 to $0.36 \mathrm{~nm}^{2} /$ molecule as the surfactant tail length increased from $\mathrm{C}_{18}$ to $\mathrm{C}_{22}$ as shown in Table 4. In our study, for C/W solutions, we observed similar behavior where the area per molecule decreased from 156 to $141 \AA^{2} /$ molecule as shown Figure 4. The higher adsorption for the $\mathrm{C}_{22}$ surfactant is influenced by the higher free surfactant concentration with the larger CMC. On the basis of these results, all the surfactant concentrations that were used for $\mathrm{C} / \mathrm{W}$ foam experiments well above the critical micelle concentration (CMC).

Foam Texture and Bulk Apparent Foam Viscosity and Morphology. Assuming a constant bubble size, increasing the aqueous external phase viscosity $\left(\mu_{e}\right), \gamma$ or the foam quality $\phi$ increases the apparent foam viscosity as follows ${ }^{55,56}$

$$
\mu_{\text {app }}=\frac{\tau_{0}}{\dot{\gamma}}+32(\phi-0.73) \mu_{e}\left(\frac{\mu_{e} \dot{\gamma} R}{\gamma}\right)^{-1 / 2}
$$

where $\dot{\gamma}$ is the shear rate, $\gamma$ is the interfacial tension, and $\mathrm{R}$ is the radius of a spherical droplet, $\mu_{e}$ is the viscosity of aqueous phase and $\phi$ is the foam quality. Thus, our hypothesis is that a large increase in $\mu_{e}$ with the formation of viscoelastic wormlike micelles aqueous phases would significantly raise $\mu_{a p p}$.

\section{Effect of Surfactant Concentration, Shear Rate and Temperature on $\mu_{a p p}$ of C/W Foam}

with OAPB. In order to choose baseline conditions for studies of foam quality and salinity, we begin by investigating the effect of surfactant concentration and shear rate on $\mu_{a p p}$. Whereas the $\mu_{a p p}$ at $0.1 \%$ OAPB in $2 \% \mathrm{KCl}$ was only $24 \mathrm{cP}$, it reached $108 \mathrm{cP}$ at $3 \%$ (Figure $7(\mathrm{~A})$ ) at $90^{\circ} \mathrm{C}$ and 0.95 quality. All of these OAPB concentrations are well above the CMC. The sharp increase in $\mu_{\text {app }}$ at $0.2 \%$ is in the range where wormlike micelles are first formed (Figure $\mathrm{S} 2$ ). An increase in the concentration beyond $0.5 \% \mathrm{OAPB}$, raises $\mu_{\text {app }}$ further by increasing the number of wormlike micelles which: (1) increases $\mu_{e}$ (Figure S2) and (2) increases the structural disjoining pressure.

At a concentration of $1 \% \mathrm{OAPB}$, the $\mathrm{C} / \mathrm{W}$ foams underwent slight shear thinning over a shear rate range of $200 \mathrm{~s}^{-1}$ to $400 \mathrm{~s}^{-1}$ in the capillary except at the highest qualities, for a flow range of $0.5 \mathrm{ml} / \mathrm{min}$ to $1 \mathrm{ml} / \mathrm{min}$ (Figure 7 (B)). Thus, we chose $200 \mathrm{~s}^{-1}$ for the shear rate in the capillary in the remainder of this study, and furthermore this shear rate is relevant for 
energized fracture fluids. ${ }^{57}$ For qualities $>0.75$, above the volume fraction of close-packedspheres, the bubbles deform against the neighboring bubbles and behave more like an elastic solid with higher sensitivity to shear rate. ${ }^{55}$

The apparent viscosity and foam morphology in the capillary is affected by the morphology of the foam generated in the upstream beadpack. For $1 \%$ OAPB in $2 \% \mathrm{KCl}$ at a high $\phi$ of 0.98 and $90^{\circ} \mathrm{C}$, the $\mu_{a p p}$ in the beadpack was a maximum of $110 \mathrm{cP}$ with continuous foam generation as seen in the view cell (Figure S10); the corresponding value in the capillary tube was 103 CP(Figure 7B). However, $\mu_{\text {app }}$ decreased sharply at a $\phi$ of 0.99 in the capillary tube. Part of this decrease may be attributed to large fluctuations in the pressure drop in the beadpack as illustrated in Figures S12. The $\mu_{a p p}$ was calculated from the average pressure drop Figure S9(B) and Figure S10. Here, the capillary pressure was too high for generation and stabilization of a uniform foam, as was also evident by incomplete filling of the view cell with foam. In contrast the pressure drop was much more constant at a $\phi$ of 0.98 (Figure S13) and uniform white foam was observed.

Highly viscous foams were seen at all temperatures. At 0.95 quality, $\mu_{a p p}$ at $50^{\circ} \mathrm{C}$ was 132 $\mathrm{CP}($ Figure $7(\mathrm{C}))$. It decreased to $78 \mathrm{CP}$ at $90^{\circ} \mathrm{C}$ and $40 \mathrm{CP}$ at $120^{\circ} \mathrm{C}$. Part of this decrease may be explained by the decrease in $\mu_{e}$ in Eq. 5 . For immobile interfaces the Reynolds velocity for film drainage

$$
V=-\frac{d h_{f}}{d t}=\frac{h_{f}^{3}}{3 \mu_{e} R_{f}^{2}} \Delta P_{f i l m}
$$

where $h_{f}$ is the thickness of the thin film, $R_{f}$ is the film radius, and $\Delta P_{f i l m}=2\left(P_{c}-\Pi_{d}\right)$ is the the film pressure that drives the lamella drainage where $\Pi_{d}$ is the disjoining pressure. ${ }^{58}$ As the temperature increases, the more rapid drainage of the lamellae (Equation 6) with the decrease in $\mu_{e}$ leads to thinner lamellae and thus greater Ostwald ripening and coalescence, which raises $\mathrm{R}$ and lowers $\mu_{\text {app }}$ according to Equation 5. 
Effect of Salinity and Foam Quality on $\boldsymbol{\mu}_{\boldsymbol{a p p}}$ at $90^{\circ} \mathrm{C}$ for OAPB. Micrographs of OAPB foams at different salt concentrations and qualities are shown in Figure 8 with $D_{s m}$ values given in Table 5. At all qualities, $D_{s m}$ decreased aw the aqueous phase was changed from DI water to $2 \%$ $\mathrm{KCl}$. As the salinity was increased further $\mathrm{D}_{\mathrm{sm}}$ remained essentially constant. For example, at $\phi=$ $0.95 \mathrm{D}_{\mathrm{sm}}$ in API brine was $34 \mu \mathrm{m}$ and in DI water was $41 \mu \mathrm{m}$. The foam apparent viscosities were studied as a function of foam quality, and salinity in Figure 9(B) and Table 5 at $90^{\circ} \mathrm{C}$. At $\phi$ of $0.95, \mu_{a p p}$ with $1 \%$ OAPB in DI water was $69 \mathrm{cP}$. For $2 \% \mathrm{KCl}$ or SSW as the aqueous phase, it increased to $78 \mathrm{cP}$, and with $8 \% \mathrm{NaCl}$ and $2 \% \mathrm{CaCl}_{2}$ (API brine) it reached $120.5 \mathrm{cP}$. Increasing the salt concentration in the aqueous solutions increased the aqueous solution viscosity, slows the lamellas drainage (Equation 6), and thus $\mu_{a p p}$ in most cases (Equation 5). According to eq 6, a higher aqueous phase viscosity may be expected to slow down lamellae thinning and subsequent Ostwald ripening and coalescence from the time the lamellae are formed in the porous media until it reaches the microscope cell Figure 1. The maintenance of the small bubbles contributes to the large $\mu_{a p p}$ according to Equation 5.

For DI water as the aqueous phase, $\mu_{a p p}$ was $76 \mathrm{cP}$ at a very high foam quality of 0.98 despite the very high $P_{c}$. For $2 \% \mathrm{KCl}$ and SSW, $\mu_{a p p}$ was even higher, $103 \mathrm{cP}$, at 0.98 quality, but it decreased for the case of API brine. This decrease at high salinity for API brine containing divalent cations is caused in part by an increase in $\gamma$ of the $\mathrm{C} / \mathrm{W}$ interface which raises the capillary pressure, despite the increase in the aqueous phase viscosity. ${ }^{59}$ The decrease was also caused by incomplete foam generation in the beadpack for API brine at 0.98 quality as was explained in the previous section.

Effect of Surfactant Tail Length. For qualities from 70 to 95\%, $\mu_{a p p}$ decreased from EAPB to OAPB to CAPB, due to changes in $\mu_{e}$ and $D_{s m}$ as explained in the next section. The apparent viscosity could not be measured for a $\phi$ of 0.98 and 0.99 for $1 \%$ OAPB in API brine in Figure $9(A)$ and Figure $9(\mathrm{~B})$, and for $1 \% \mathrm{EAPB}$ in $2 \% \mathrm{KCl}$ in Figure 10 as only discrete slugs of foam were observed to pass through the view cell. At these aqueous phase concentrations, the zero shear aqueous phase viscosities were above $2000 \mathrm{cP}$ (Table 2). A shear rate of $400 \mathrm{~s}^{-1}$ in the beadpack the low viscosity $\mathrm{CO}_{2}$ phase did not transmit a sufficient shear stress to break up the aqueous 
phase into the very thin aqueous lamellae, which would be required at the high $\phi$. However, for a higher beadpack shear rate up to $2300 \mathrm{~s}^{-1}$, continuous foam formation was observed with shear thinning behavior as shown in Figure S11. In summary, for very high values of $\phi$, there is an optimum aqueous phase viscosity that is low enough to enable foam generation (in the beadpack) and high enough to inhibit foam destabilization in the capillary tube by lamellar drainage.

\section{Scaling Law Model for the Bulk $\mu_{a p p}$ in the Capillary Tubes at $90^{\circ} \mathrm{C}$ with $2 \% \mathrm{KCl}$. The} viscosity for $1 \%$ EAPB $\left(\mathrm{C}_{22}\right)$ in $2 \% \mathrm{KCl}$ at 0.95 quality was $87 \mathrm{cP}$ and for the $1 \% \mathrm{OAPB}\left(\mathrm{C}_{18}\right)$ in $2 \%$ $\mathrm{KCl}$ is $78 \mathrm{cp}$. However, for $1 \% \mathrm{CAPB}$ (short tail) in $2 \% \mathrm{KCl}$ it was only $57 \mathrm{cP}$ (Figure 10). According to Equation 5, the more viscous aqueous phase give rise to more viscous foam, despite the modestly smaller $\mathrm{D}_{s m}$ for OAPB (Table 5). At 0.98 quality for $2 \% \mathrm{KCl}$, continuous foam was produced in the beadpack for OAPB, but not for EAPB, as it was too viscous. CAPB solution foams had the highest initial bubble size of $61 \mu \mathrm{m}$. In addition to these factors, the size is also influenced by $\gamma$ as described by the model of Otsubo and Prudhomme (Figure 11). ${ }^{60}$ The viscosity data at $90^{\circ} \mathrm{C}$ and 0.98 quality from Table 2 and Table 4 for $1 \%$ EAPB in $2 \% \mathrm{KCl}, 1 \%$ OAPB in DI, $2 \% \mathrm{KCl}, \mathrm{SSW}, \mathrm{API}$ brine and $1 \% \mathrm{CAPB}$ in $2 \% \mathrm{KCl}$ are linear on a log-log plot of $D_{s m} \mu_{a p p} / \gamma \mu_{e}$ versus $\mu_{e} \dot{\gamma}$. From the exponent of -0.76 in the fitted line, it may easily be shown that $\mu_{\text {app }} \propto D_{s m}^{-1} \mu_{e}^{0.24}$ indicating a significant influence of $\mu_{\mathrm{e}}$ and a stronger contribution from $D_{s m}$. At 0.95 quality, $\mu_{a p p} \propto D_{s m}^{-1} \mu_{e}^{0.09}$ indicating less sensitivity to $\mu_{e}$. The stronger influence of $\mu_{e}$ at 0.98 may be expected given the higher capillary pressures with the very thin lamella is present. Here, the reduction of the lamellae drainage rate from the large $\mu_{e}$ becomes even more important. However, $\mu_{\mathrm{e}}$ also influences the bubble size via stabilization of the lamellae films and thus has an important influence on $\mu_{\text {app }}$. The scaling law of $\mu_{\text {emulsion }} \propto D_{\text {sm }}^{-1} \mu_{e}^{0.32}$ determined by Prudhomme et al ${ }^{60}$ for $80 \% \mathrm{v} / \mathrm{v}$ oil-water emulsions shows a greater sensitivity to $\mu_{\mathrm{e}}$.

C/W Foam Stability Determined by Microscopy. The foam bubble sizes were continuously measured after stopping flow in the microscopy cell over time in order to quantify the foam 
stability in terms of Ostwald ripening for $2 \% \mathrm{KCl}$ and a quality of 0.95 for all three surfactants (Figure 12). As shown in Figure 13, the foam generated with 1\% EAPB was the most stable as the $D_{s m}$ increased very slowly from $43 \mu \mathrm{m}$ to $123 \mu \mathrm{m}$ over 22 hours. For $1 \%$ OAPB, Dsm increased from about $30 \mu \mathrm{m}$ to $190 \mu \mathrm{m}$ over 16 hours. For the $1 \%$ CAPB foam generated with the non-viscoelastic aqueous phase, $D_{s m}$ increased very rapidly from $56 \mu \mathrm{m}$ to $166 \mu \mathrm{m}$ over only 1.6 hours.

The Ostwald ripening (coarsening) rate in the Lifshitz, Slyozov, and Wagner (LSW) model is given $b^{61}$

$$
\Omega_{3}=\frac{d D_{s m}^{3}}{d t}=\frac{64 \gamma D_{d i f f} S V_{m}}{9 R T} F
$$

where $S$ is the bulk solubility of the dispersed phase, and $V_{m}$ is the molar volume of the dispersed phase. $F$ is a correction factor to account for the effects of small diffusion length and high internal phase conditions. The linear behavior of $\mathrm{D}_{\mathrm{sm}}{ }^{3}$ presented in Figure 13 for each surfactant is consistent with LSW theory (Equation 7). At 0.95 quality, $\Omega_{3}$ decreased by a factor of 6 for the foam made with $1 \%$ OAPB in $2 \% \mathrm{KCl}$ viscoelastic solution relative to the case of $1 \%$ CAPB, and by a factor of 34 for the foam made with the $1 \%$ EAPB in $2 \% \mathrm{KCl}$. As described by Eq. 6 , increasing the lamella viscosity with each viscoelastic surfactant solution reduces the drainage velocity, such that thicker lamellae are maintained. The coarsening rate decreases given the decrease in the diffusion rate of $\mathrm{CO}_{2}$ through the thicker more viscous lamellae, and the more tortuous path of the 3D branched network of wormlike micelles. ${ }^{30,62,29,63}$ For EAPB at 1320 minutes, many very small bubbles smaller than $10 \mu \mathrm{m}$ are present that were much less prevalent for the other surfactants, given the slower rate for Ostwald ripening prevented their disappearance. The ability to slow down Ostwald ripening is particularly important for high pressure $\mathrm{CO}_{2}$ as it is quite soluble in water, on the order of several wt. \%, far more than that of gases such as $\mathrm{N}_{2}$.

\section{Conclusion}

Viscoelastic wormlike micelles aqueous solutions of environmentally friendly carboxybetaines surfactants with long unsaturated tails, C18 and C22, are formed over a wide 
range of salinity and $\mathrm{pH}$ and utilized to stabilize $\mathrm{C} / \mathrm{W}$ foams. With a dilute $1 \mathrm{wt}$.\% solution of only a single zwitterionic surfactant, highly viscous and stable C/W foam > $100 \mathrm{cP}$ were generated over a wide range of temperatures up to $120^{\circ} \mathrm{C}$ and quality up to 0.99 . In contrast, our previous study required 4 wt.\% of a mixture of a cationic and anionic surfactant, as well as concentrated electrolyte to form ultralow water content $\mathrm{C} / \mathrm{W}$ foams. ${ }^{28}$ Whereas the packing parameter for the surfactant (EAPB) with a $C_{22}$ tail was sufficient to form strong wormlike micelles even in DI water with a zero shear viscosity of more than $2000 \mathrm{cP},{ }^{24}$ salinity of API brine was required for OAPB with a $\mathrm{C}_{18}$ tail to achieve similar viscosities. The increase in wormlike micelles entanglements with added salts or adjusted $\mathrm{pH}$ was observed by complex rheology. The aqueous phase stability of betaine viscoelastic surfactants at wide range of $\mathrm{pH}$ and salt concentration make the surfactants solutions applicable at a wide range of applications.

The aqueous viscoelastic systems enabled the generation and stabilization of high apparent viscosity foam $130 \mathrm{cP}$, and at low water conditions with only $2 \%$ volume fraction surfactant solution, as a consequence of the slow drainage of the viscoelastic lamellae films. The high $\mu_{a p p}$ is correlated to the large aqueous phase viscosity and small bubble size, $~ 34 \mu \mathrm{m}$. With the slow film drainage, the thicker lamellas were observed via microscopy to lower the rate of Ostwald ripening (by 34 fold) and coalescence. Lower IFT might make foam generation easier with smaller initial bubble size, while viscous aqueous phase help stabilizing the foam. The highly viscous and stable foam at high temperature and pressure could thus be used in reservoir conditions as energized ultralow water content fracturing fluids with reduced water utilization and disposal.

\section{$\underline{\text { Acknowledgments }}$}

This work was supported by the Department of Energy under Grant DE-FE0013723, “Development of Nanoparticle-stabilized Foams to Improve Performance of Water-less 
Hydraulic Fracturing" and the Welch Foundation (F-1319). The authors also acknowledge Dr. Srinivasa R. Raghavan for helpful discussions. 


\section{References}

1. Adamsky, F. A.; Beckman, E. J. Inverse Emulsion Polymerization of Acrylamide in Supercritical Carbon Dioxide. Macromolecules 1994, 27, 312-314.

2. Reverchon, E.; Adami, R.; Cardea, S.; Porta, G. D. Supercritical fluids processing of polymers for pharmaceutical and medical applications. The Journal of Supercritical Fluids 2009, 47 (3), 484-492.

3. Bal, D. K.; Patra, S.; Ganguly, S. Effectiveness of foam-gel formulation in homogenizing the CO 2 front during subsurface sequestration. Journal of Natural Gas Science and Engineering 2015, 27, 9941004.

4. Jafari, M.; Cao, S. C.; Jung, J. Geological CO 2 sequestration in saline aquifers: Implication on potential solutions of China's power sector. Resources, Conservation and Recycling 2016.

5. Enick, R. M.; Olsen, D.; Ammer, J.; Schuller, W. Mobility and Conformance Control for CO2 EOR via Thickeners, Foams, and Gels - A Literature Review of 40 years of Research and Pilot Tests. SPE 154122, presented at SPE Improved Oil Recovery Symp., Tulsa, OK, Apr. 14-18. 2012.

6. Farajzadeh, R.; Andrianov, A.; Krastev, R.; Hirasaki, G. J.; Rossen, W. R. Foam-oil interaction in porous media: Implications for foam assisted enhanced oil recovery. Advances in Colloid and Interface Science 2012, 183-184, 1-13.

7. Phillips, A. M.; Couchman, D. D. High temperature rheology of $\mathrm{CO} 2$ foam fracturing fluids. Proceedings of the Annual Southwestern Petroleum Short Course 1987, 34th, 102-6.

8. $\quad$ Chen, Y.; Elhag, A. S.; Cui, L.; Worthen, A. J.; Reddy, P. P.; Noguera, J. A.; Ou, A. M.; Ma, K.; Puerto, M.; Hirasaki, G. J.; Nguyen, Q. P.; Biswal, S. L.; Johnston, K. P. CO2-in-Water Foam at Elevated Temperature and Salinity Stabilized with a Nonionic Surfactant with a High Degree of Ethoxylation. Industrial \& Engineering Chemistry Research 2015, 54 (16), 4252-4263.

9. Eftekhari, A. A.; Krastev, R.; Farajzadeh, R. In Foam Stabilized by Fly-Ash Nanoparticles for Enhancing Oil Recovery, SPE 175382, presented at SPE Kuwait Oil and Gas Show and Conference, Mishref, Kuwait, Oct. 11-14, 2015.

10. Worthen, A. J.; Bagaria, H. G.; Chen, Y.; Bryant, S. L.; Huh, C.; Johnston, K. P. Nanoparticlestabilized carbon dioxide-in-water foams with fine texture. Journal of Colloid and Interface Science 2013, 391 (1), 142-151.

11. Verbist, G.; Weaire, D.; Phelan, R. Rheology and Drainage of Liquid Foams. In Foams and Emulsions, Sadoc, J. F.; Rivier, N., Eds.; Kluwer Academic Publishers: Dordrecht, Netherlands, 1999; Vol. 354, pp 303-314.

12. Rio, E.; Drenckhan, W.; Salonen, A.; Langevin, D. Unusually stable liquid foams. Advances in Colloid and Interface Science 2014, 205, 74-86.

13. Rio, E.; Biance, A.-L. Thermodynamic and Mechanical Timescales Involved in Foam Film Rupture and Liquid Foam Coalescence. ChemPhysChem 2014, 15 (17), 3692-3707.

14. Miles, G. D.; Shedlovsky, L.; Ross, J. Foam Drainage. The Journal of Physical Chemistry 1945, 49 (2), 93-107.

15. Walker, L. M. Rheology and structure of worm-like micelles. Current Opinion in Colloid \& Interface Science 2001, 6 (5-6), 451-456.

16. Chu, Z.; Dreiss, C. A.; Feng, Y. Smart wormlike micelles. Chemical Society Reviews 2013, 42 (17), 7174-7203.

17. Ezrahi, S.; Tuval, E.; Aserin, A. Properties, main applications and perspectives of worm micelles. Advances in Colloid and Interface Science 2006, 128-130, 77-102.

18. Dreiss, C. A. Wormlike micelles: where do we stand? Recent developments, linear rheology and scattering techniques. Soft Matter 2007, 3 (8), 956-970.

19. Zhang, Y.; Feng, Y. CO2-induced smart viscoelastic fluids based on mixtures of sodium erucate and triethylamine. Journal of Colloid and Interface Science 2015, 447, 173-181. 
20. Raghavan, S. R.; Fritz, G.; Kaler, E. W. Wormlike Micelles Formed by Synergistic Self-Assembly in Mixtures of Anionic and Cationic Surfactants. Langmuir 2002, 18 (10), 3797-3803.

21. Zhang, C.; Li, Z.; Sun, Q.; Wang, P.; Wang, S.; Liu, W. CO2 foam properties and the stabilizing mechanism of sodium bis(2-ethylhexyl)sulfosuccinate and hydrophobic nanoparticle mixtures. Soft Matter 2015.

22. Maeda, H.; Tanaka, S.; Ono, Y.; Miyahara, M.; Kawasaki, H.; Nemoto, N.; Almgren, M. Reversible Micelle-Vesicle Conversion of Oleyldimethylamine Oxide by $\mathrm{pH}$ Changes. The Journal of Physical Chemistry B 2006, 110 (25), 12451-12458.

23. Chu, Z.; Feng, Y. pH-switchable wormlike micelles. Chemical Communications 2010, 46 (47), 9028-9030.

24. Kumar, R.; Kalur, G. C.; Ziserman, L.; Danino, D.; Raghavan, S. R. Wormlike Micelles of a C22Tailed Zwitterionic Betaine Surfactant: From Viscoelastic Solutions to Elastic Gels. Langmuir 2007, 23 (26), 12849-12856.

25. Langevin, D. Aqueous Foams: A Field of Investigation at the Frontier Between Chemistry and Physics. ChemPhysChem 2008, 9 (4), 510-522.

26. Langevin, D. Influence of interfacial rheology on foam and emulsion properties. Advances in Colloid and Interface Science 2000, 88 (1,2), 209-222.

27. Xue, Z.; Worthen, A.; Qajar, A.; Robert, I.; Bryant, S. L.; Huh, C.; Prodanović, M.; Johnston, K. P. Viscosity and stability of ultra-high internal phase $\mathrm{CO} 2$-in-water foams stabilized with surfactants and nanoparticles with or without polyelectrolytes. Journal of Colloid and Interface Science 2016, 461, 383395.

28. Xue, Z.; Worthen, A. J.; Da, C.; Qajar, A.; Ketchum, I. R.; Alzobaidi, S.; Huh, C.; Prodanović, M.; Johnston, K. P. Ultradry Carbon Dioxide-in-Water Foams with Viscoelastic Aqueous Phases. Langmuir 2016, 32 (1), 28-37.

29. Fameau, A.-L.; Saint-Jalmes, A.; Cousin, F.; Houinsou Houssou, B.; Novales, B.; Navailles, L.; Nallet, F.; Gaillard, C.; Boué, F.; Douliez, J.-P. Smart Foams: Switching Reversibly between Ultrastable and Unstable Foams. Angewandte Chemie International Edition 2011, 50 (36), 8264-8269.

30. Varade, D.; Carriere, D.; Arriaga, L. R.; Fameau, A. L.; Rio, E.; Langevin, D.; Drenckhan, W. On the origin of the stability of foams made from catanionic surfactant mixtures. Soft Matter 2011, 7 (14), 6557-6570.

31. Monteux, C.; Fuller, G. G.; Bergeron, V. Shear and Dilational Surface Rheology of Oppositely Charged Polyelectrolyte/Surfactant Microgels Adsorbed at the Air-Water Interface. Influence on Foam Stability. The Journal of Physical Chemistry B 2004, 108 (42), 16473-16482.

32. Chen, Y.; Elhag, A. S.; Worthen, A. J.; Reddy, P. P.; Ou, A. M.; Hirasaki, G. J.; Nguyen, Q. P.; Biswal, S. L.; Johnston, K. P. High Temperature CO2-in-Water Foams Stabilized with Cationic Quaternary Ammonium Surfactants. Journal of Chemical \& Engineering Data 2016, 61 (8), 2761-2770.

33. Enick, R. M.; Olsen, D. K.; Ammer, J. R.; Schuller, W. In Mobility and Conformance Control for CO2 EOR via Thickeners, Foams, and Gels--A Literature Review of 40 Years of Research and Pilot Tests, SPE improved oil recovery symposium, 2012; Society of Petroleum Engineers.

34. Danov, K. D.; Kralchevska, S. D.; Kralchevsky, P. A.; Ananthapadmanabhan, K. P.; Lips, A. Mixed Solutions of Anionic and Zwitterionic Surfactant (Betaine): Surface-Tension Isotherms, Adsorption, and Relaxation Kinetics. Langmuir 2004, 20 (13), 5445-5453.

35. Zeng, Y.; Muthuswamy, A.; Ma, K.; Wang, L.; Farajzadeh, R.; Puerto, M.; Vincent-Bonnieu, S.; Eftekhari, A. A.; Wang, Y.; Da, C.; Joyce, J. C.; Biswal, S. L.; Hirasaki, G. J. Insights on Foam Transport from a Texture-Implicit Local-Equilibrium Model with an Improved Parameter Estimation Algorithm. Industrial \& Engineering Chemistry Research 2016, 55 (28), 7819-7829. 
36. Wang, Y.; Ge, J.; Zhang, G.; Jiang, P.; Zhang, W.; Lin, Y. Adsorption behavior of dodecyl hydroxypropyl sulfobetaine on limestone in high salinity water. RSC Advances 2015, 5 (73), 5973859744.

37. Worthen, A. J.; Tran, V.; Cornell, K. A.; Truskett, T. M.; Johnston, K. P. Steric stabilization of nanoparticles with grafted low molecular weight ligands in highly concentrated brines including divalent ions. Soft Matter 2016, 12 (7), 2025-2039.

38. Ranka, M.; Brown, P.; Hatton, T. A. Responsive Stabilization of Nanoparticles for Extreme Salinity and High-Temperature Reservoir Applications. ACS Applied Materials \& Interfaces 2015, 7 (35), 1965119658.

39. Garcia, M. T.; Campos, E.; Marsal, A.; Ribosa, I. Fate and effects of amphoteric surfactants in the aquatic environment. Environment International 2008, 34 (7), 1001-1005.

40. Weers, J. G.; Rathman, J. F.; Axe, F. U.; Crichlow, C. A.; Foland, L. D.; Scheuing, D. R.; Wiersema, R. J.; Zielske, A. G. Effect of the intramolecular charge separation distance on the solution properties of betaines and sulfobetaines. Langmuir 1991, 7 (5), 854-867.

41. Ono, Y.; Shikata, T. Dielectric Behavior of Aqueous Micellar Solutions of Betaine-Type Surfactants. The Journal of Physical Chemistry B 2005, 109 (15), 7412-7419.

42. Kumar, R.; Raghavan, S. R. Photogelling fluids based on light-activated growth of zwitterionic wormlike micelles. Soft Matter 2009, 5 (4), 797-803.

43. Beaumont, J.; Louvet, N.; Divoux, T.; Fardin, M.-A.; Bodiguel, H.; Lerouge, S.; Manneville, S.; Colin, A. Turbulent flows in highly elastic wormlike micelles. Soft Matter 2013, 9 (3), 735-749.

44. Hashimoto, K.; Imae, T. Rheological properties of aqueous solutions of alkyl-and oleyldimethylamine oxides. Spinnability and viscoelasticity. Langmuir 1991, 7 (8), 1734-1741.

45. Maeda, H.; Yamamoto, A.; Souda, M.; Kawasaki, H.; Hossain, K. S.; Nemoto, N.; Almgren, M. Effects of Protonation on the Viscoelastic Properties of Tetradecyldimethylamine Oxide Micelles. The Journal of Physical Chemistry B 2001, 105 (23), 5411-5418.

46. Kathmann, E. E.; White, L. A.; McCormick, C. L. Water soluble polymers: $69 . \mathrm{pH}$ and electrolyte responsive copolymers of acrylamide and the zwitterionic monomer 4-(2-acrylamido-2methylpropyldimethylammonio) butanoate: synthesis and solution behaviour. Polymer 1997, 38 (4), 871-878.

47. Zajac, J.; Chorro, C.; Lindheimer, M.; Partyka, S. Thermodynamics of Micellization and Adsorption of Zwitterionic Surfactants in Aqueous Media. Langmuir 1997, 13 (6), 1486-1495. 48. Kawasaki, H.; Souda, M.; Tanaka, S.; Nemoto, N.; Karlsson, G.; Almgren, M.; Maeda, H. Reversible Vesicle Formation by Changing pH. The Journal of Physical Chemistry B 2002, 106 (7), 15241527.

49. Yao, R.; Qian, J.; Li, H.; Yasin, A.; Xie, Y.; Yang, H. Synthesis and high-performance of a new sarcosinate anionic surfactant with a long unsaturated tail. RSC Advances 2014, 4 (6), 2865-2872. 50. Maeda, H.; Kakehashi, R. Effects of protonation on the thermodynamic properties of alkyl dimethylamine oxides. Advances in Colloid and Interface Science 2000, 88 (1-2), 275-293.

51. Fischer, P.; Rehage, H.; Grüning, B. Linear Flow Properties of Dimer Acid Betaine Solutions with and without Changed lonic Strength. The Journal of Physical Chemistry B 2002, 106 (42), 11041-11046.

52. Johnson, K. M.; Fevola, M. J.; McCormick, C. L. Hydrophobically modified acrylamide-based polybetaines. I. Synthesis, characterization, and stimuli-responsive solution behavior. Journal of Applied Polymer Science 2004, 92 (1), 647-657.

53. Lee, C. T.; Ryoo, W.; Smith, P. G.; Arellano, J.; Mitchell, D. R.; Lagow, R. J.; Webber, S. E.; Johnston, K. P. Carbon Dioxide-in-Water Microemulsions. J. Am. Chem. Soc. 2003, 125, 3181-3189.

54. Feng, D.; Zhang, Y.; Chen, Q.; Wang, J.; Li, B.; Feng, Y. Synthesis and Surface Activities of Amidobetaine Surfactants with Ultra-long Unsaturated Hydrophobic Chains. Journal of Surfactants and Detergents 2012, 15 (5), 657-661. 
55. Princen, H. M.; Kiss, A. D. Rheology of foams and highly concentrated emulsions. IV. An experimental study of the shear viscosity and yield stress of concentrated emulsions. Journal of Colloid and Interface Science 1989, 128 (1), 176-87.

56. Hirasaki, G. J.; Lawson, J. B. Mechanisms of Foam Flow in Porous Media: Apparent Viscosity in Smooth Capillaries. Society of Petroleum Engineers Journal 1985, 176-190.

57. Ribeiro, L. H.; Sharma, M. M. Multiphase Fluid-Loss Properties and Return Permeability of Energized Fracturing Fluids. SPE Production \& Operations 2012, 27 (3), 265-277.

58. Ivanov, I. B.; Kralchevsky, P. A. Stability of emulsions under equilibrium and dynamic conditions. Colloids and Surfaces A: Physicochemical and Engineering Aspects 1997, 128, 155-175.

59. Weissenborn, P. K.; Pugh, R. J. Surface Tension of Aqueous Solutions of Electrolytes: Relationship with Ion Hydration, Oxygen Solubility, and Bubble Coalescence. Journal of Colloid and Interface Science 1996, 184 (2), 550-563.

60. Otsubo, Y.; Prud'homme, R. K. Rheology of oil-in-water emulsions. Rheologica Acta 1994, 33 (1), 29-37.

61. Adkins, S. S.; Chen, X.; Chan, I.; Torino, E.; Nguyen, Q. P.; Sanders, A. W.; Johnston, K. P. Morphology and Stability of CO2-in-Water Foams with Nonionic Hydrocarbon Surfactants. Langmuir 2010, 26 (8), 5335-5348.

62. Georgieva, D.; Cagna, A.; Langevin, D. Link between surface elasticity and foam stability. Soft Matter 2009, 5 (10), 2063-2071.

63. Espert, A.; Klitzing, R. v.; Poulin, P.; Colin, A.; Zana, R.; Langevin, D. Behavior of Soap Films Stabilized by a Cationic Dimeric Surfactant. Langmuir 1998, 14 (15), 4251-4260. 


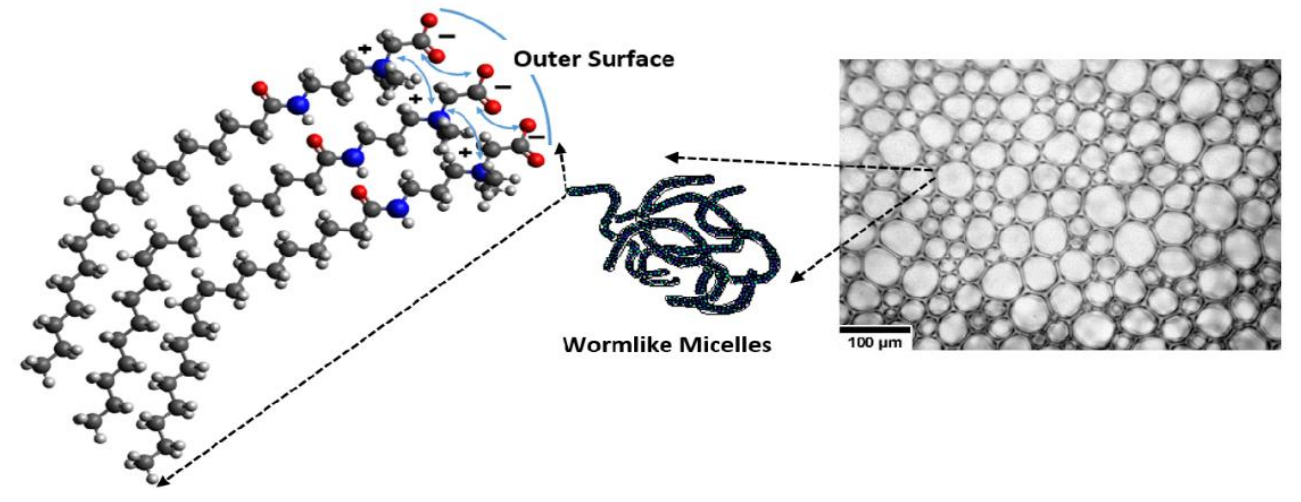


Note: All tables + Figure1+Figure 5+ Figure 8 +Figure 12 are 2 columns; the rest of the figures can be 1 column.

\section{Figures and Tables}

Table 1. Concentrations and structures of the surfactants.

\begin{tabular}{|c|c|c|}
\hline Surfactant & Structure & $\begin{array}{c}\% \\
\text { Concentration }\end{array}$ \\
\hline CAPB & & $39.4 \%$ \\
\hline OAPB & & $31 \%$ \\
\hline EAPB & & $100 \%$ \\
\hline
\end{tabular}




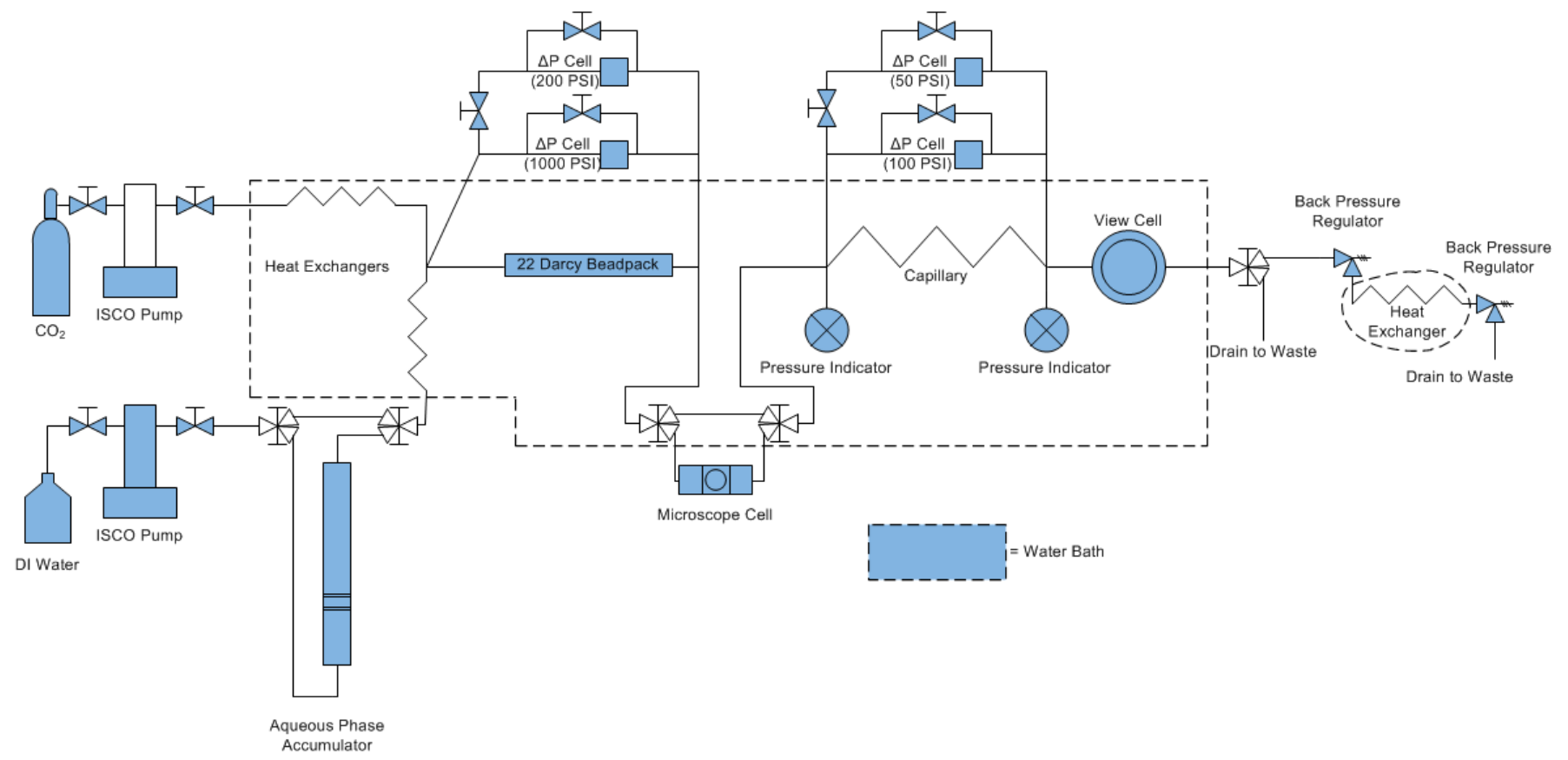

Figure 1. Flow apparatus with 22 Darcy beadpack for $\mathrm{C} / \mathrm{W}$ foam generation and measurement of pressure drop across the beadpack and downstream capillary tube to determine apparent viscosities, and microscope cell to observe foam texture stability.

Table 2. Extrapolated zero and $200 \mathrm{~s}^{-1}$ shear viscosities for the aqueous surfactant solutions at $1 \%$ concentration.

\begin{tabular}{|c|c|c|c|c|}
\hline Surfactant & Aq. solution & $\mathbf{p H}$ & $\begin{array}{c}\text { Zero Shear } \\
\text { Viscosity (cP) }\end{array}$ & $\begin{array}{c}\mathbf{2 0 0 ~ s}^{-1} \text { Shear } \\
\text { Viscosity (cP) }\end{array}$ \\
\hline EAPB & $2 \% \mathrm{KCl}$ & 4.0 & 4400 & 32.5 \\
\hline EAPB & $2 \% \mathrm{KCl}$ & 9.8 & 2250 & 12.5 \\
\hline OAPB & $2 \% \mathrm{KCl}$ & 2.0 & 5200 & 12.6 \\
\hline OAPB & $2 \% \mathrm{KCl}$ & 4.0 & 200 & 11.6 \\
\hline OAPB & $2 \% \mathrm{KCl}$ & 7.3 & 90 & 10.7 \\
\hline OAPB & API brine & 7.3 & 2300 & 15.5 \\
\hline OAPB & SSW & 7.3 & 140 & 10.7 \\
\hline OAPB & DI & 7.3 & 70 & 8.0 \\
\hline CAPB & $2 \% \mathrm{KCl}$ & 4.0 & 2 & 1.0 \\
\hline
\end{tabular}


(A)

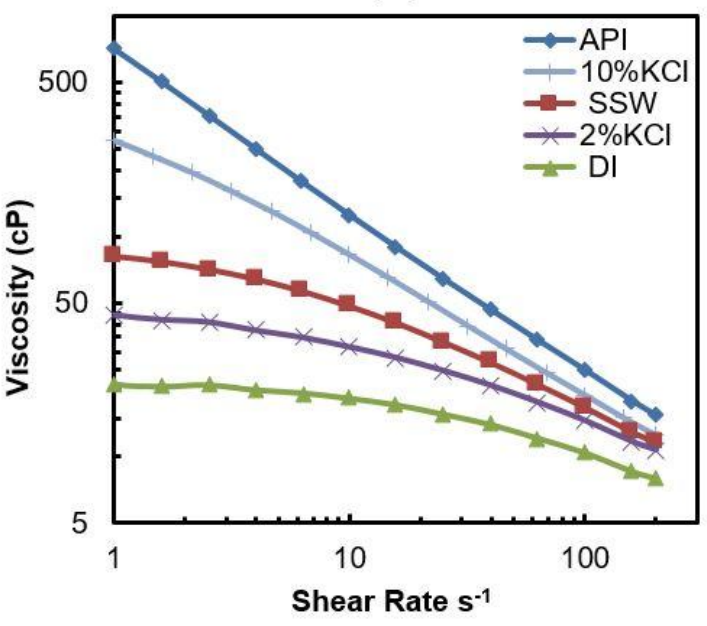

(B)

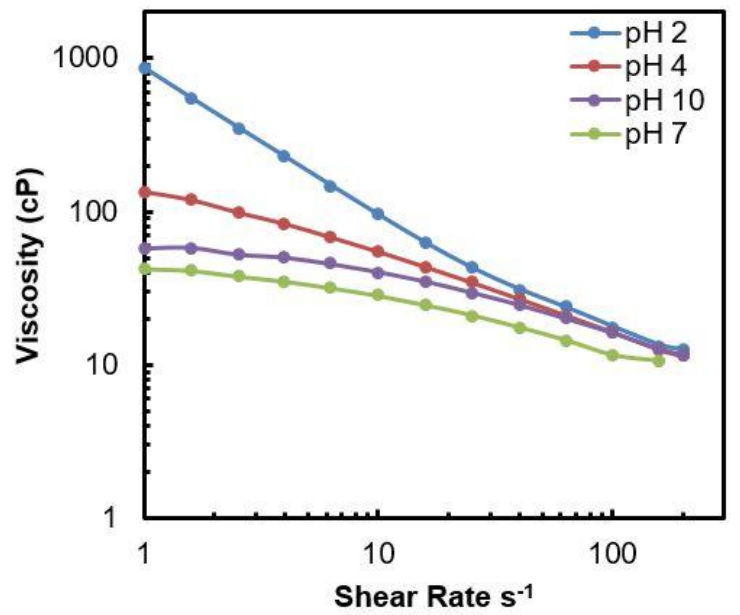

Figure 2. Viscosity versus shear rate for $1 \%$ OAPB aqueous solution (A) Effect of salinity. (B) Effect of $\mathrm{pH}$. The data were obtained using a cone and plate rheometer at atmospheric pressure and room temperature. 


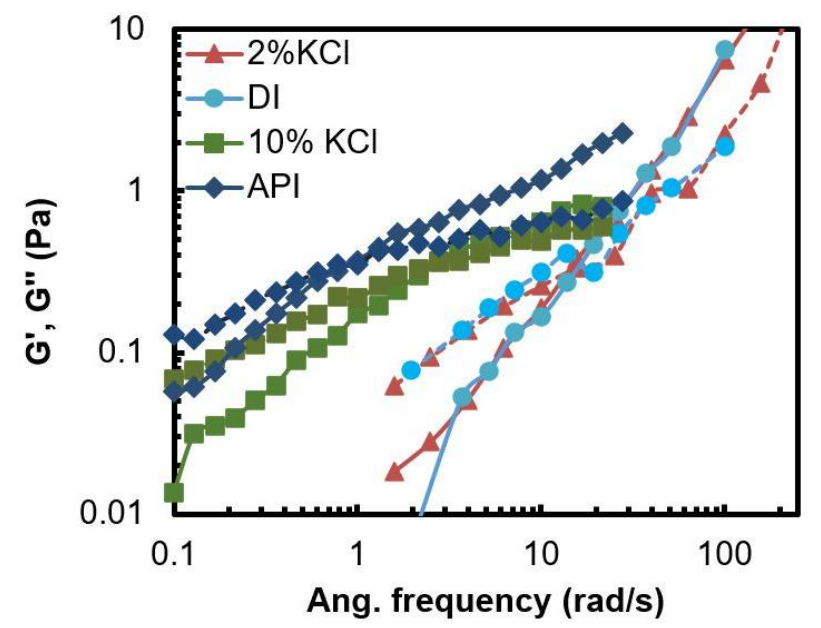

Figure 3. Complex rheology for $1 \%$ OAPB solution at different salt concentrations without any pH adjustment. --- $\mathrm{G}^{\prime \prime}$, - $\mathrm{G}^{\prime}$, circle $\mathrm{DI}$ water, rectangular $2 \% \mathrm{KCl}$, square $10 \% \mathrm{KCl}$, daimond $\mathrm{API}$ brine.

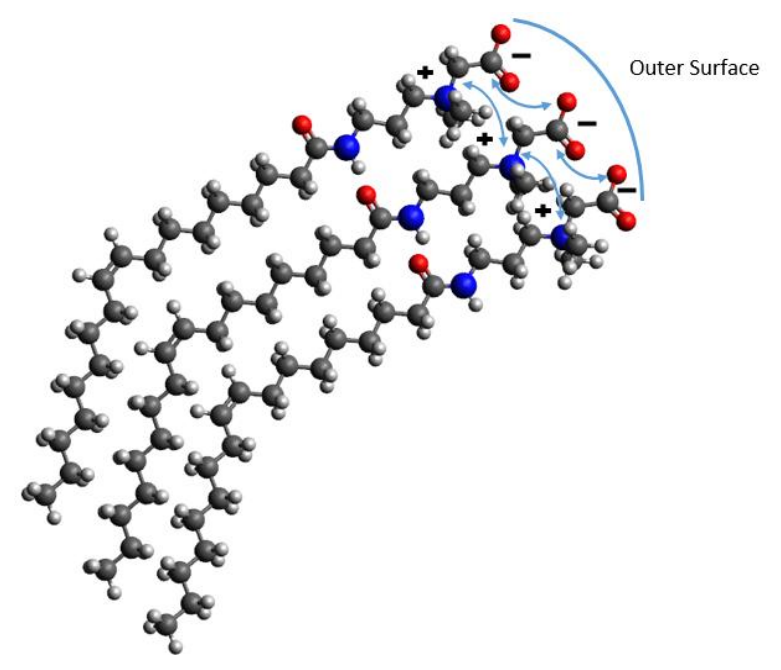

Figure 4. A schematic to illustrate the packing fraction of the OAPB in the axial region of rod-like micelles. The small head group and the bent tails raise the packing fraction. Atoms are colored grey (Carbon), red (Oxygen), blue (Nitrogen), and white (Hydrogen). 
(A)

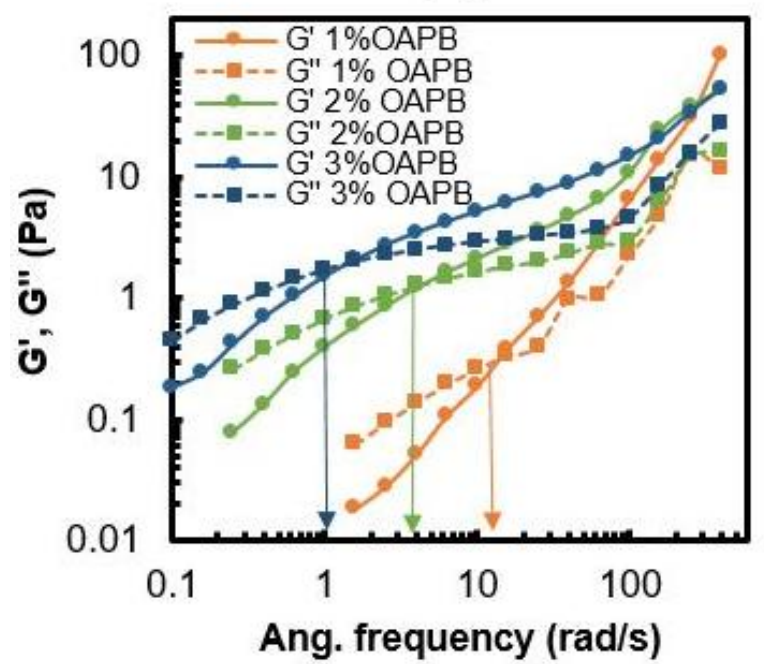

(C)

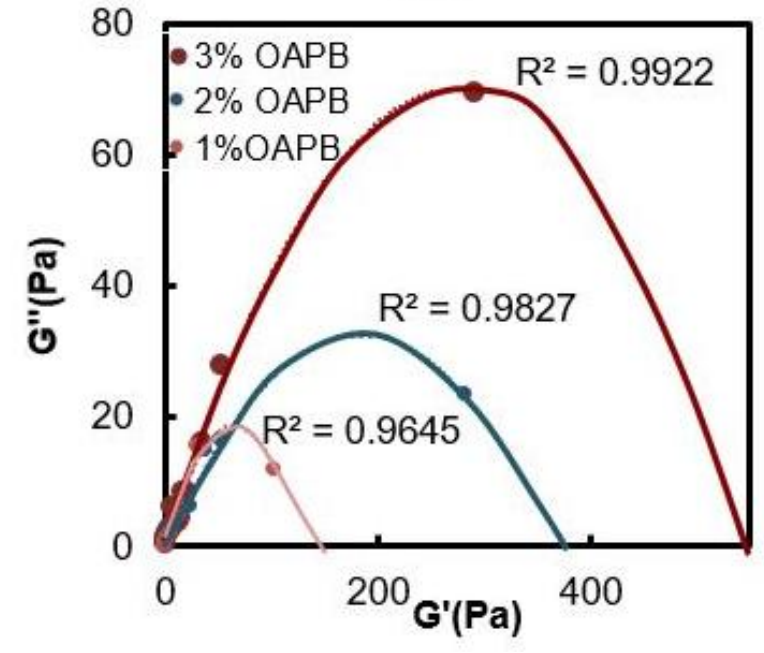

(B)

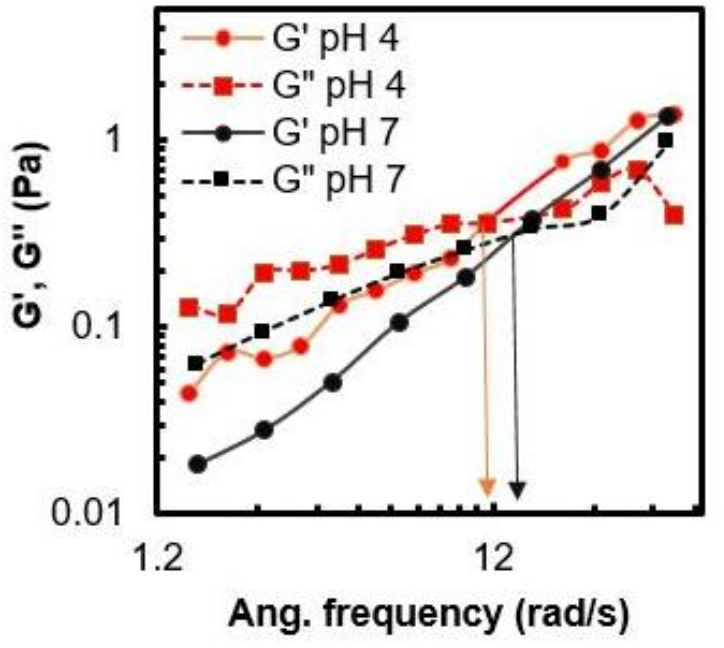

(D)

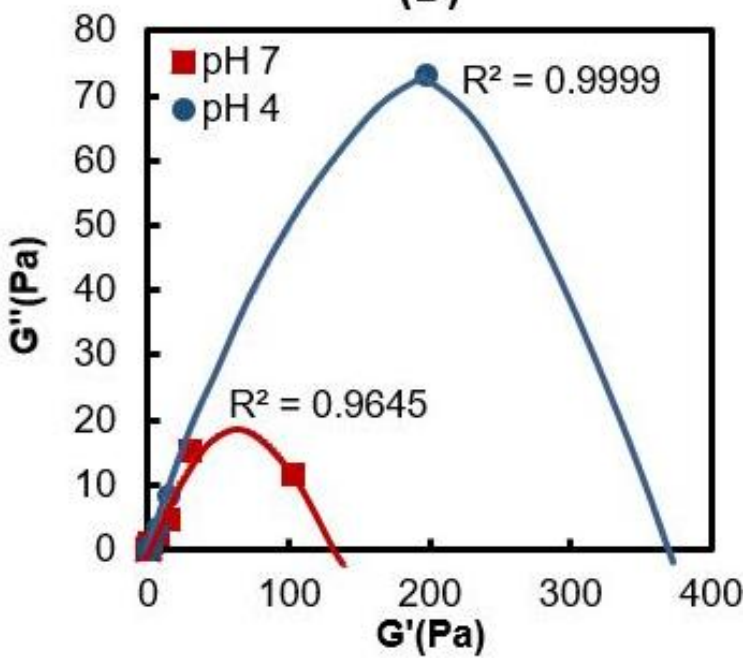

Figure 5. Rheology of OAPB aqueous solutions in $2 \% \mathrm{KCl}$ brine, .--- $\mathrm{G}^{\prime \prime},-\mathrm{G}^{\prime}$.(A) Concentration effect on OAPB in $2 \% \mathrm{KCl},(\mathrm{B}) \mathrm{PH}$ effect on $1 \% \mathrm{OAPB},(\mathrm{C})$ and $(\mathrm{D})$ are Cole-Cole plots for concentration and $\mathrm{pH}$ effect.

Table 3. Crossover frequency and relaxation times for Maxwell fluids with relaxation times ranked from high to low measured at atmospheric pressure and ambient $\mathrm{T}$.

\begin{tabular}{|c|c|c|c|c|}
\hline System & Aq. solution & $\mathrm{pH}$ & $\begin{array}{c}\text { Crossover } \\
\text { Frequency } \\
\text { (rad/s) }\end{array}$ & $\begin{array}{c}\text { Relaxation time } \\
(\mathrm{ms})\end{array}$ \\
\hline
\end{tabular}




\begin{tabular}{|c|c|c|c|c|}
\hline $1 \%$ EAPB & $2 \% \mathrm{KCl}$ & 4.0 & $<<0.1$ & $>>1000$ \\
\hline $1 \%$ EAPB & $2 \% \mathrm{KCl}$ & 9.8 & $<<0.1$ & $>>1000$ \\
\hline $1 \%$ OAPB & API & 7.25 & 1.19 & 840 \\
\hline $3 \%$ OAPB & $2 \% \mathrm{KCl}$ & 7.25 & 1.59 & 630 \\
\hline $2 \%$ OAPB & $2 \% \mathrm{KCl}$ & 7.25 & 3.98 & 251 \\
\hline $1 \%$ OAPB & $2 \% \mathrm{KCl}$ & 4.0 & 11.62 & 63 \\
\hline $1 \%$ OAPB & $2 \% \mathrm{KCl}$ & 7.25 & 15.85 & 52 \\
\hline $1 \%$ OAPB & $\mathrm{DI}$ & 7.25 & 19.31 & \\
\hline
\end{tabular}

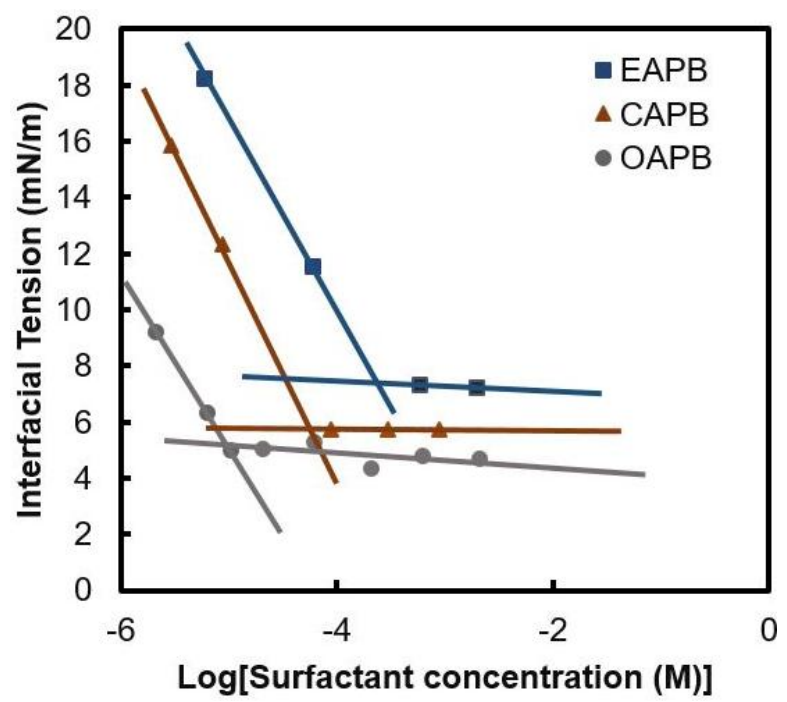

Figure 6. Reverse $\mathrm{CO}_{2}$ pendant drop interfacial tension measurements for $\mathrm{EAPB}, \mathrm{CAPB}$, and $\mathrm{OAPB}$ versus concentration in $2 \% \mathrm{KCl}$ solution at $25^{\circ} \mathrm{C}$ and 3000 psig.

Table 4. Interfacial properties at $\mathrm{CO}_{2} / 2 \% \mathrm{KCl}$ interface from Figure 4 on the basis of the GibbsAdsorption equation.

\begin{tabular}{|l|l|l|l|l|l|}
\hline Surfactant & $\begin{array}{l}\mathbf{C O}_{2} \\
\text { density } \\
(\mathbf{g} / \mathbf{m L})\end{array}$ & $\begin{array}{l}\mathrm{IFT}_{\mathrm{cmc}} \\
(\mathbf{m N} / \mathbf{m})\end{array}$ & $\begin{array}{l}\mathbf{C M C} \\
(\mathbf{m m o l} / \mathbf{L})\end{array}$ & $\begin{array}{l}\Gamma^{*} \mathbf{1 0}^{4} \\
\left(\mathbf{m o l} / \mathbf{m}^{2}\right)\end{array}$ & $\begin{array}{l}\mathbf{A}_{\mathbf{m}} \\
\left(\AA^{2} / \text { molecule }\right)\end{array}$ \\
\hline CAPB & 0.91 & 5.7 & 0.07 & 0.013 & 128 \\
\hline OAPB & 0.91 & 4.9 & 0.01 & 0.012 & 156 \\
\hline EAPB & 0.91 & 7.3 & 0.2 & 0.011 & 141 \\
\hline
\end{tabular}


Table 5. Aqueous phase and bulk C/W foam apparent viscosity at a shear rate of $200 \mathrm{~s}^{-1}$ based on a flow rate of $0.5 \mathrm{ml} / \mathrm{min}$ for qualities of 0.95 and 0.98 . All the experiments were at 3000 psig.

\begin{tabular}{|c|c|c|c|c|c|c|c|c|}
\hline System & $\begin{array}{c}\text { Aq. } \\
\text { solution }\end{array}$ & $\begin{array}{c}\mathrm{T} \\
\left({ }^{\circ} \mathrm{C}\right)\end{array}$ & $\begin{array}{l}\text { Aq. Vis- } \\
\text { cosity } \\
\text { (cP) }\end{array}$ & $\begin{array}{c}\text { IFT } \\
\mathrm{mN} / \mathrm{m} \\
24^{\circ} \mathrm{C}\end{array}$ & $\begin{array}{c}\text { Foam } \\
\text { App.Viscosity } \\
\text { at } 0.95 Q(\mathrm{cP}) \\
\text { and } 90^{\circ} \mathrm{C}\end{array}$ & $\begin{array}{c}\text { Initial } \\
D_{\text {sm }}(\mu \mathrm{m}) \mathrm{a} \\
\text { t } 0.95 \mathrm{Q} \\
\text { and } 90^{\circ} \mathrm{C}\end{array}$ & $\begin{array}{c}\text { Foam } \\
\text { App.Vis- } \\
\text { cosity at } \\
0.98 Q \\
(\mathrm{cP}) \text { and } \\
90^{\circ} \mathrm{C}\end{array}$ & $\begin{array}{c}\text { Initial } \\
\mathrm{D}_{\mathrm{sm}}(\mu \mathrm{m}) \\
\text { at } 0.98 \mathrm{Q} \\
\text { and } \\
90^{\circ} \mathrm{C}\end{array}$ \\
\hline $\begin{array}{c}1 \% \\
\text { EAPB }\end{array}$ & $2 \% \mathrm{KCl}$ & 90 & 32.5 & 6.8 & 87 & 51 & $(-)$ & $(-)$ \\
\hline $\begin{array}{c}1 \% \\
\text { OAPB }\end{array}$ & $2 \% \mathrm{KCl}$ & 50 & 11.6 & 3.9 & 132 & $(-)$ & 135 & $(-)$ \\
\hline $\begin{array}{c}1 \% \\
\text { OAPB }\end{array}$ & $2 \% \mathrm{KCl}$ & 90 & 11.6 & 3.9 & 78 & 35 & 103 & 46 \\
\hline $\begin{array}{c}1 \% \\
\text { OAPB }\end{array}$ & $2 \% \mathrm{KCl}$ & 120 & 11.6 & 3.9 & 40 & $(-)$ & 20 & $(-)$ \\
\hline $\begin{array}{c}1 \% \\
\text { OAPB }\end{array}$ & API & 90 & 15.5 & $(-)$ & 120.5 & 34 & $(-)$ & 48 \\
\hline $\begin{array}{c}1 \% \\
\text { OAPB }\end{array}$ & SSW & 90 & 11.7 & $(-)$ & 7 & 36 & 101 & 47 \\
\hline $\begin{array}{c}1 \% \\
\text { OAPB }\end{array}$ & $\mathrm{DI}$ & 90 & 8.0 & $(-)$ & 69 & 41 & 76 & 64 \\
\hline $\begin{array}{c}1 \% \\
\text { CAPB }\end{array}$ & $2 \% \mathrm{KCl}$ & 90 & 1 & 5.8 & 57 & 61 & 54 & 75 \\
\hline
\end{tabular}




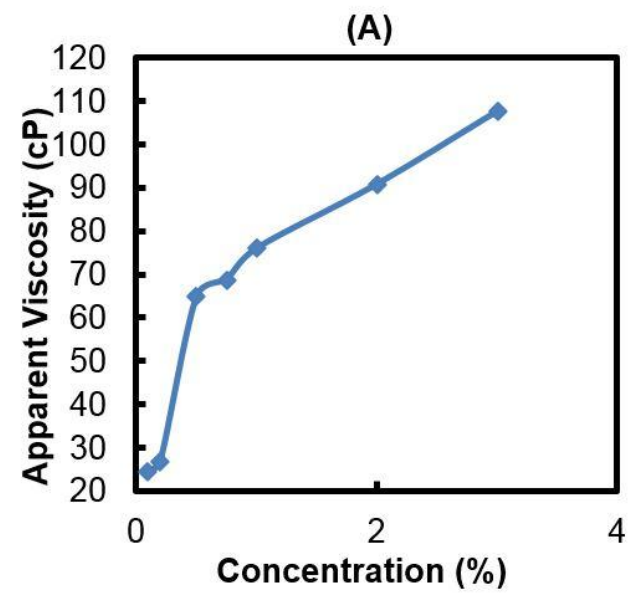

(B)

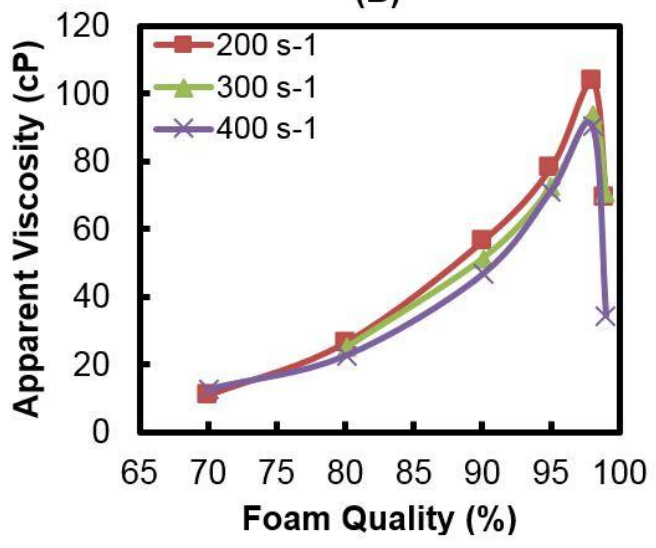

(C)

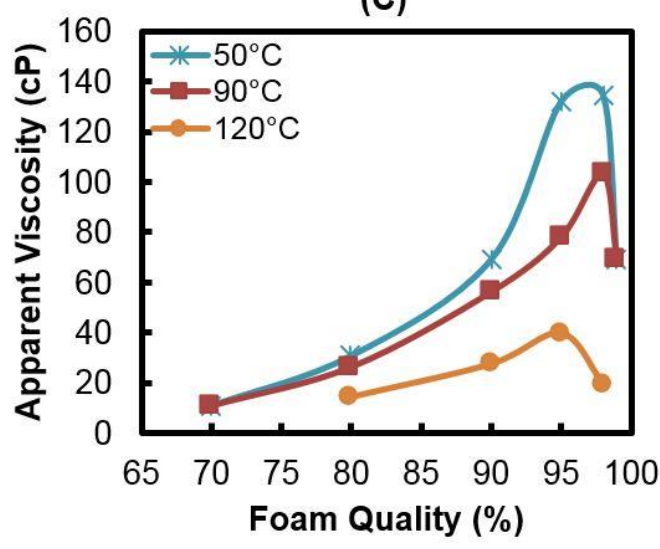

Figure 7. (A) Concentraion effect on bulk $\mathrm{C} / \mathrm{W}$ foam apparent viscosity for OAPB in $2 \% \mathrm{KCl}$ at a quality of $0.95,3000 \mathrm{psig}$, and $90^{\circ} \mathrm{C}$. (B) Shear rate effect on $\mathrm{C} / \mathrm{W}$ foam viscosity for $1 \% \mathrm{OAPB}$ in $2 \% \mathrm{KCl}$ at $90^{\circ} \mathrm{C}$ and 3000 psig. (C) Temperature Effect at $200 \mathrm{~s}^{-1}$ and 3000 psig for $1 \% \mathrm{KCl}$ in $2 \%$ $\mathrm{KCl}$. 


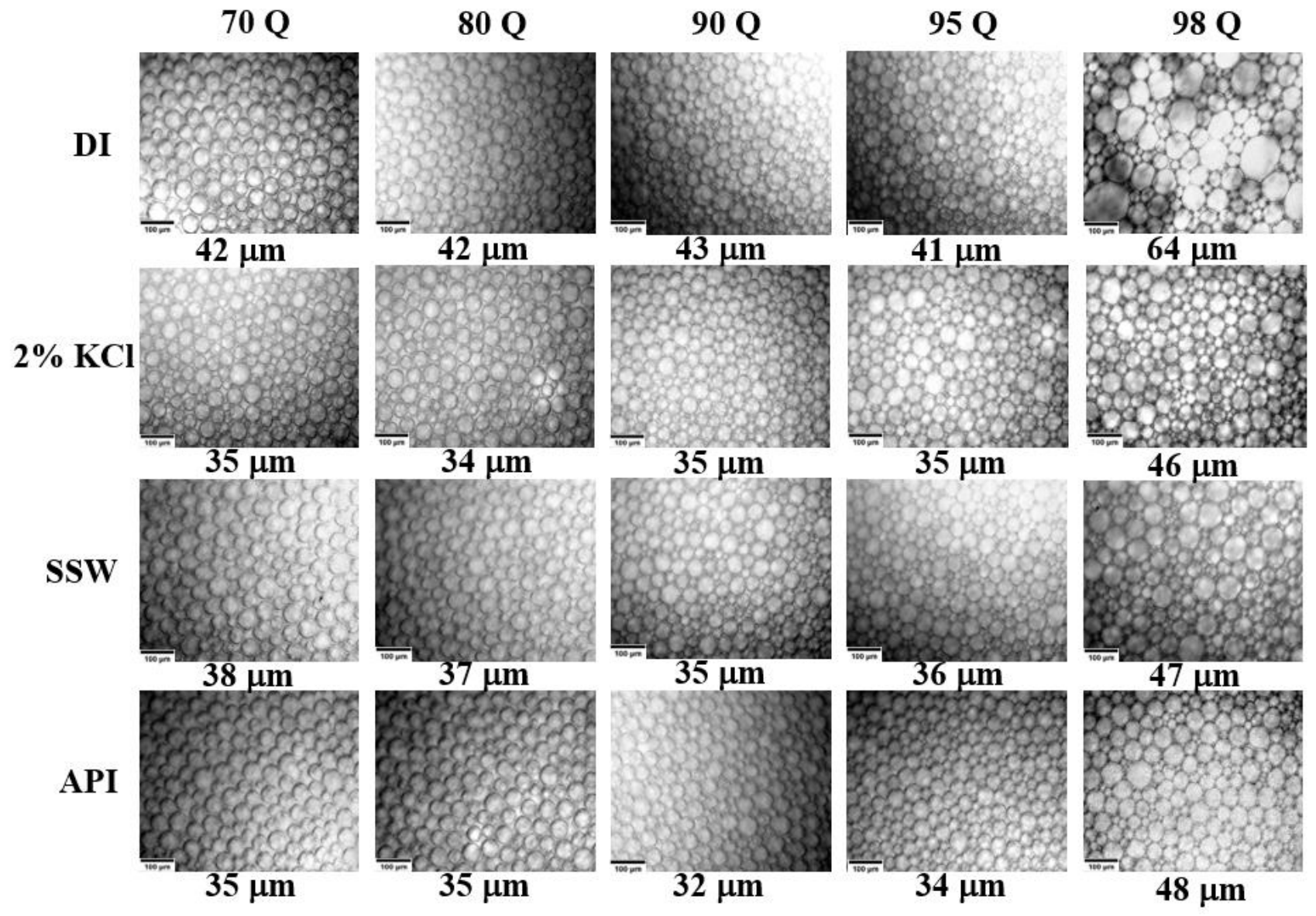

Figure 8. Micrographs of $1 \%$ OAPB C/W foam at different qualities and salinities at $90^{\circ} \mathrm{C}$ and 3000 psig. The average bubble size is indicated below each micrograph. The scale bar is $100 \mu \mathrm{m}$ for all of the images. 

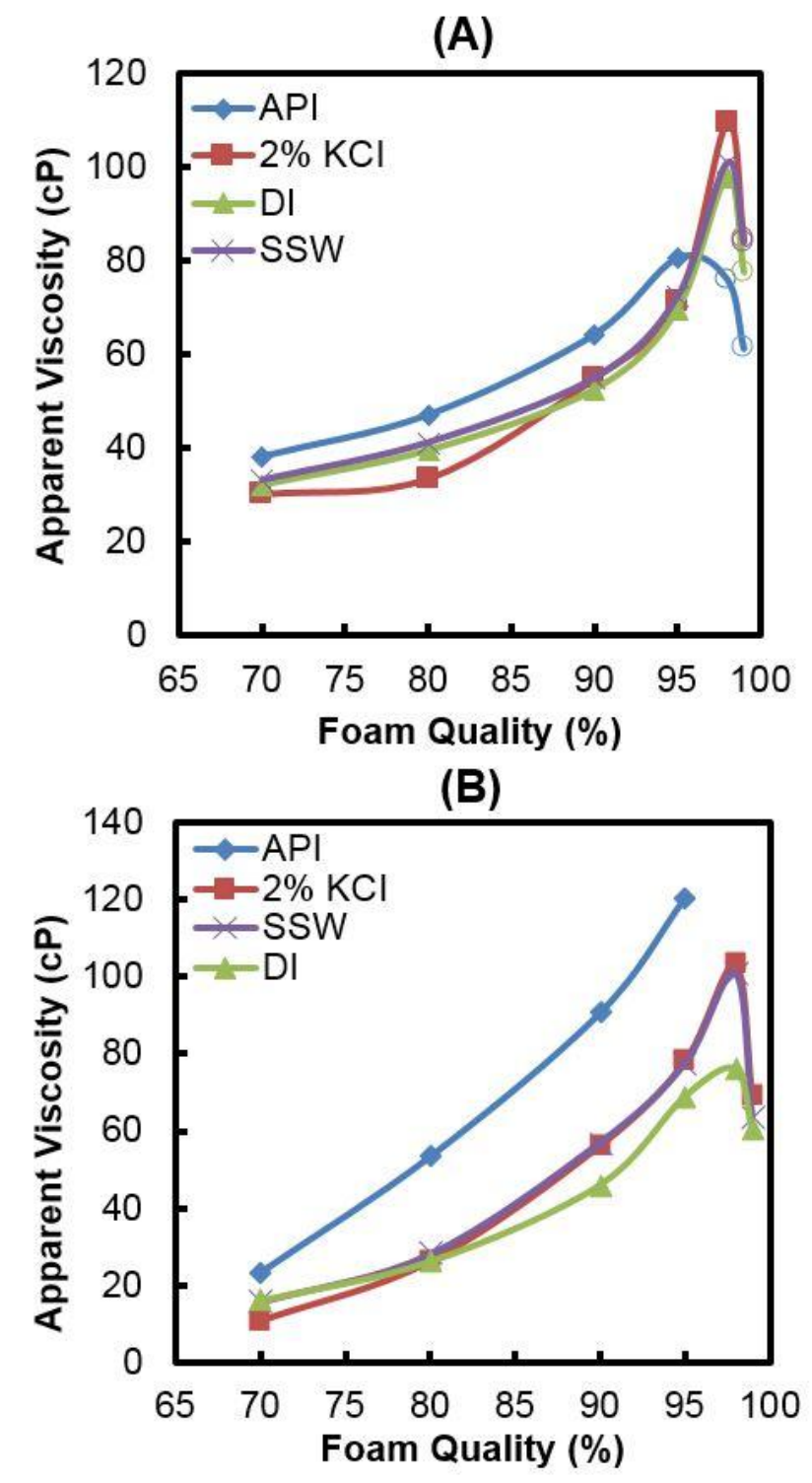

Figure 9. Effect of salt and foam quality on bulk C/W foam apparent viscosity for $1 \%$ OAPB at $90^{\circ} \mathrm{C}$ and 3000 psig. (A) foam apparent viscosity in a $22 \mathrm{D}$ beadpack at $400 \mathrm{~s}^{-1}$ shear rate. (B) Apparent foam viscosity in the capillary tube measured at $200 \mathrm{~s}^{-1}$. (0) symbol indicates a large fluctuation in the pressure drop in the beadpack. 


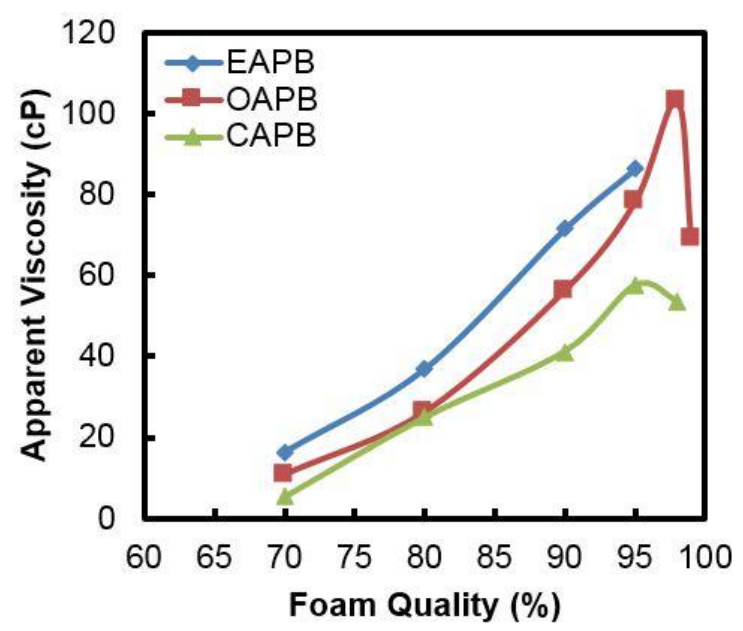

Figure 10. Bulk C/W foam apparent viscosity for $1 \% \mathrm{EAPB}, \mathrm{OAPB}$, and CAPB in $2 \% \mathrm{KCl}$ at $90^{\circ} \mathrm{C}$ and 3000 psig at $200 \mathrm{~s}^{-1}$ shear rate.

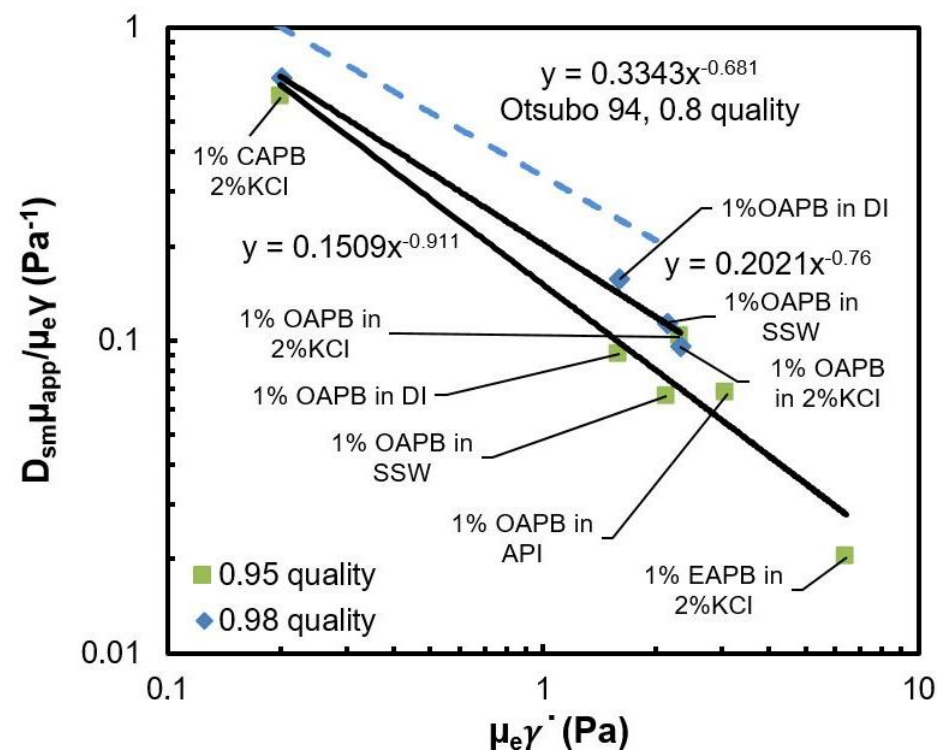

Figure 11. Reduced apparent viscosity versus product of aqueous phase viscosity and shear rate for C/W foams at 0.95 (squares) and 0.98 (diamonds) quality. Points are labeled for $1 \%$ OAPB in $\mathrm{DI}, 2 \% \mathrm{KCl}, \mathrm{SSW}$, API brine, $1 \% \mathrm{EAPB}$ in $2 \% \mathrm{KCl}$ and $1 \% \mathrm{CAPB}$ in $2 \% \mathrm{KCl}$ at $90^{\circ} \mathrm{C}$ and 3000 psig. Dashed line is for oil-in-water emulsions at 0.8 quality (dashed line) of Otsubo et al. ${ }^{1}$ 


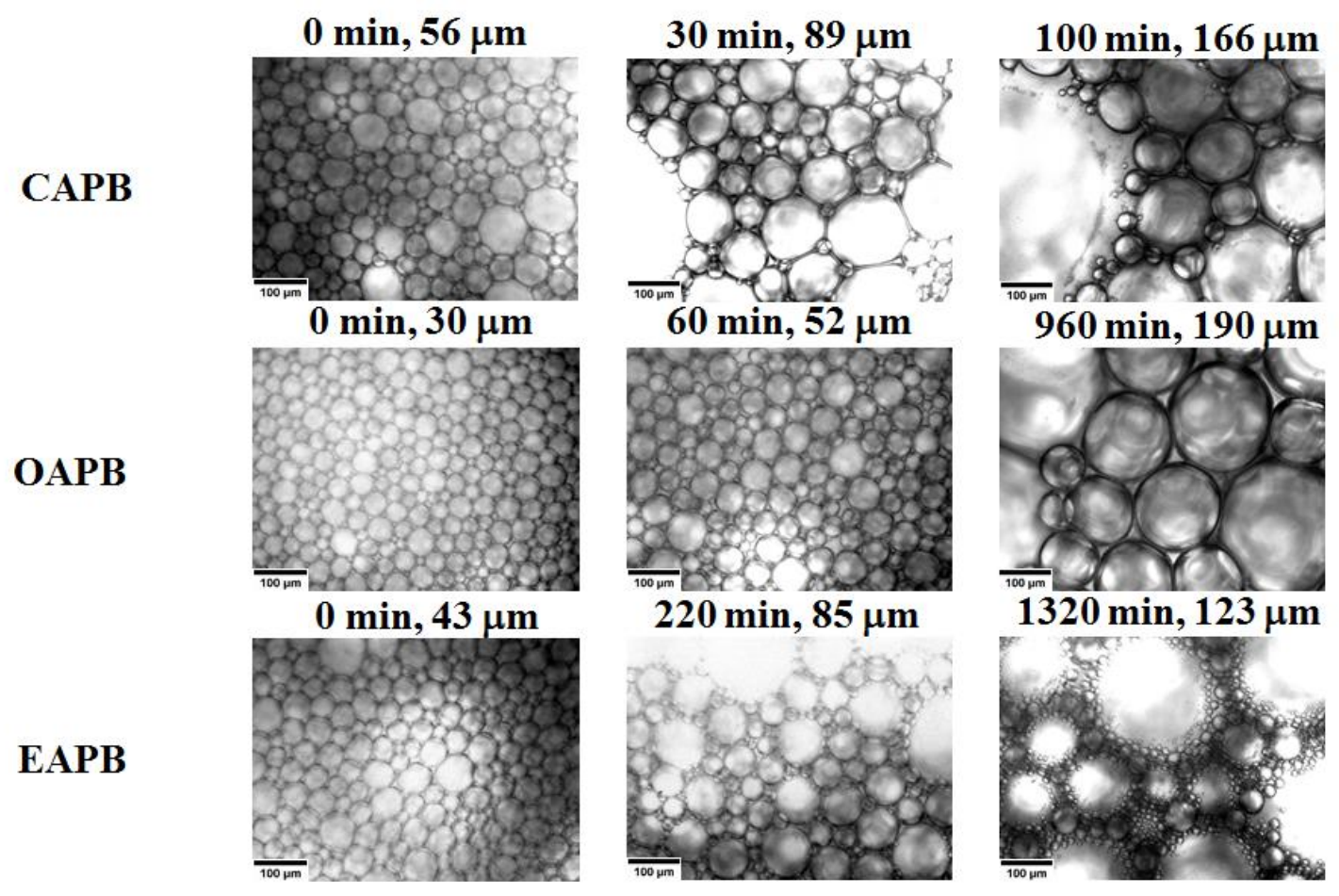

Figure 12. Micrographs of evolution of $\mathrm{C} / \mathrm{W}$ foam texture in time for $1 \%$ surfactant in $2 \% \mathrm{KCl}$ at $25^{\circ} \mathrm{C}, 3000 \mathrm{psig}$, and 0.95 quality. The time and average bubble size of each picture is written on the top of each image. The scale bar is $100 \mu \mathrm{m}$.

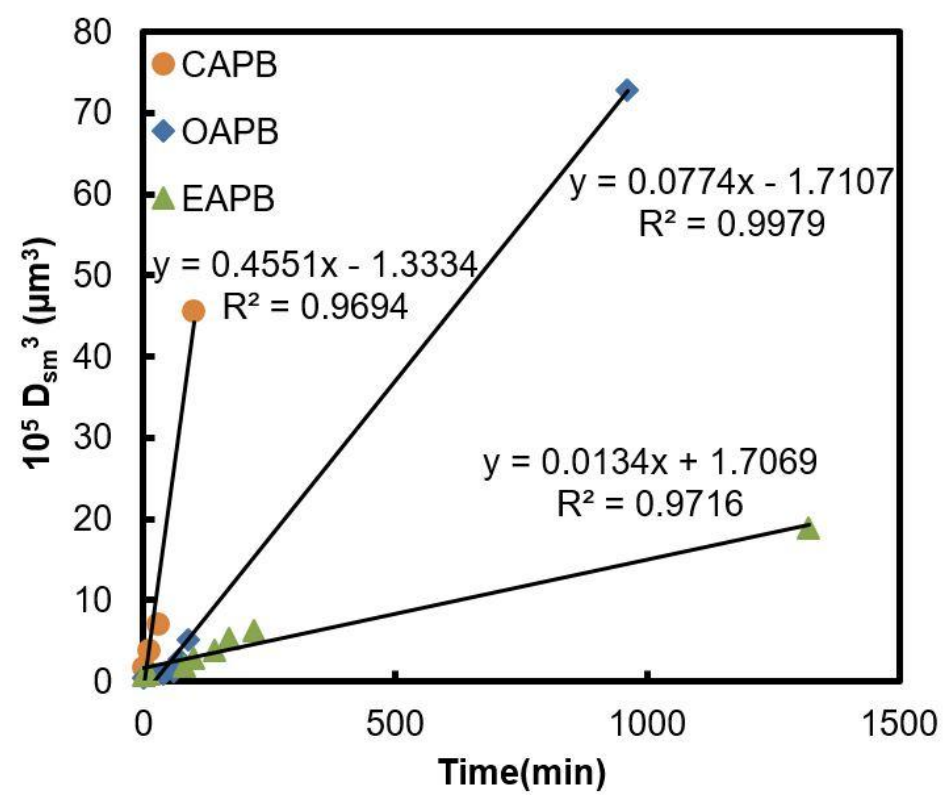


Figure 13. Static C/W foam stability in terms of $D_{s m}$ versus time for $1 \%$ surfactant in $2 \% \mathrm{KCl}$ brine at $25^{\circ} \mathrm{C}, 3000$ pisg, and 0.95 quality.

1. Otsubo, Y.; Prud'homme, R. K. Rheology of oil-in-water emulsions. Rheologica Acta 1994, 33 (1), 29-37. 